\title{
Patrimônio geológico e mineiro no nordeste do Brasil
}

\author{
Geological and mining heritage in northeastern Brazil \\ MARCOS ANTONIO LEITE DO NASCIMENTO*, ANTONIO JOSÉ DOURADO ROCHA**, \\ MARJORIE CSEKO NOLASCO***. \\ *Universidade Federal do Rio Grande do Norte - marcos@geologia.ufrn.br \\ **Serviço Geológico do Brasil (CPRM) - antonio.dourado@cprm.gov.br \\ ***Universidade Estadual de Feira de Santana - marjorie.nolasco@gmail.com
}

\section{Resumo}

O Nordeste brasileiro apresenta uma diversidade geológica ímpar e que faz parte do patrimônio geológico nacional. Esta região, em termos de minerais, rochas, fósseis, paisagens (relevo), além de outros elementos da geodiversidade, apresenta exemplos dos mais didáticos e completos, indo desde rochas antigas do embasamento cristalino (> 3 bilhões de anos) até as coberturas de dunas (< 5 mil anos) e sedimentos recentes em seus leitos de rios, lagos e lagunas. Muitos desses exemplos constituem potenciais monumentos que vêm atualmente despertando, além do interesse científico-didático, também turístico, histórico e cultural. No momento temos ao todos 164 geossítios cadastrados, espalhados em diferentes bases, constituindo 14 categorias temáticas, com destaque para a sedimentologia, paleontologia e geomorfologia. São inúmeros os exemplos de patrimônio geológico-mineiro identificados, porém convém lembrar, que esses são apenas uma pequena amostra do que o Nordeste possui. Conhecer melhor este patrimônio e protegê-lo é de suma importância, haja vista que ele possui a particularidade de ser único e irrecuperável: uma vez deteriorado estará perdido para sempre!

Palavras-chave: Patrimônio Geológico; Patrimônio Mineiro; Nordeste.

\section{Abstract}

The Brazilian Northeast has a unique geological diversity and is part of the national geological heritage. This region, in terms of minerals, rocks, fossils, landscapes (relief), and other elements of geodiversity, presents examples of the most instructive and comprehensive, ranging from ancient rocks of the crystalline basement ( $>3$ billion years) until the coverage dunes ( $<5000$ years) and recent sediments in their beds of rivers, lakes and lagoons. Many of these examples are potential monuments, which are now awakening, as well as scientific interest-didactic, too touristic, historical and cultural. At the moment we have all 164 geosites, scattered in different bases, constituting 14 thematic categories, with emphasis on sedimentology, paleontology and geomorphology. There are countless examples of geologicalmining heritage identified but it should be remembered that these are only a small sample of what the Northeast has. Better understand this heritage and protecting it is importance, given that it has the particularity of being unique and irretrievable: once decayed is lost forever!

Key words: Geological Heritage; Mining Heritage; Northeast.

\section{INTRODUÇÃO}

Recursos Naturais são todas as partes componentes da natureza, exceto o homem e os seus produtos, que possam ser pelo mesmo aproveitadas de diferentes formas. Assim a palavra recurso natural esta vinculada a uso e não envolve valor intrínseco dado a natureza ou as divisões nela estabelecidas pelo homem. Os recursos dividem-se em bióticos e abióticos, em grandes termos. Os primeiros são em sua maioria renováveis se respeitados os seus ciclos geracionais e os segundos envolvem recursos similares conduzidos por ciclos puramente geoquímicos como a água e o ar (autolimpantes) e não renováveis, ou seja, de uso não retornável ao meio, a exemplo dos minerais, rochas, recursos energéticos (carvão mineral, hulha, óleo) cujo uso pelo homem implica na sua supressão da natureza. Aqui vale apontar que estes últimos podem sofrer, depois da retirada e primeiro uso, reciclagem, reutilização, reduzindo a necessidade de retirada primária, como todos os demais recursos. Mas não podem ser criados, plantados, ou ter seu ciclo de reconstituição respeitado, pois não apresentam tal processo, exceto no tempo geológico, ao qual o homem e suas necessidades não pode se submeter ou esperar.

Dentro destes recursos ditos energéticos ou minerais fósseis estão alguns cujo uso o homem não consegue mais abrir mão, apesar de conseguir reduzir seu volume de retirada primária, pois apresentam importância hoje similar a água, ar e energia. Como exemplo pode-se citar: o vidro (sílica ou quartzo), os plásticos (petróleo), diversos metais como o ferro, chumbo, alumínio; os materiais de construção como blocos, tijolos, filtros e telhas (argilas) areia, fragmento de rocha, o cimento (calcário); os minerais de usos tecnológicos como terras raras, titânio, ouro, diamante; entre muitos outros. Eles atendem no dia a dia, na saúde, na habitação, na escola, no avanço da ciência e da cultura. Como se pode perceber a relação entre o homem e os minerais e rochas é intensa e antiga e deste longo aprendizado tem resultado toda(s) a(s) 
civilização(ões) humana(s), conclui-se o homem é minero-dependente!

Deve se destacar que a configuração geológica define a própria escolha de locais de fixação e urbanização, ou colonização e dominação, pela disponibilidade de recursos. Por isto mesmo o desenho da ocupação ou urbis denuncia, ainda hoje, os dois mais importantes deles: a conformação da paisagem no quesito acesso e segurança e a presença da água- um recurso necessário a vida e de múltiplos usos, ao longo da qual se extende toda a civilização, para não adentrar na conquista do fogo.

A maioria dos recursos citados tem origem direta ou indireta na mineração, assim sendo a mina é a expressão do uso dos recursos abióticos, a mais clara e uma das mais antigas marcas da relação entre a sociedade e a geodiversidade e da dependência geológica da humanidade.

Patrimônio diz de herança, daquilo que fala sobre a identidade de um grupo, de um local, região, do mundo! Algo relevante, marcante em cada nível ou em todos eles, para o Homem. Pode ter várias tipologias, como o recurso, as mais amplas delas são material e imaterial, além de natural ou cultural que podem se mesclar com os anteriores. Em ambas as divisões, os primeiros grupos (material e cultural) são fartamente conhecidos e trabalhados, como em edificações, tombamento de monumentos, prédios, moveis, esculturas e mesmo em alguns raros casos, em áreas mineiras especialmente de ouro.

Já os termos Patrimônio Natural e Imaterial são menos difundidos, refere-se o primeiro a paisagens, artes rupestres pré-históricas e outros sítios arqueológicos e, o segundo, a memória no seu aspecto não documental e ao que não é tocável, mas relaciona-se a manifestações culturais e sociais, como festejos e costumes, a música, as históricas contadas e ao artesanato.

Contextualizado os conceitos e suas definições, será que as minas e a mineração fazem parte da memória, ou mais amplamente da herança de um povo? Deve-se registrar que é mais comum e usual o reconhecimento do rural no agropecuário, no extrativismo animal e vegetal como atividades de povos tradicionais. Talvez, por desconhecimento ou um silêncio pouco esclarecido, ou ainda por não serem os povos mineiros dados a conversas ou aparições, o extrativismo mineral, a atividade minera ou ainda mais longe garimpeira, não é reconhecida formalmente. Entretanto, em diversos países da Europa e America Latina, especialmente de influência espanhola, já se reconhece e indica a existência de um patrimônio mineiro.

Uma mina expõe o patrimônio geológico de uma região como poucos pontos do planeta, permitindo a formação de profissionais diversos e o entendimento do funcionamento da "nossa casa" Terra, assim ela guarda patrimônio dito natural, do tipo geológico.
Também guarda toda a memória das técnicas e das dificuldades dos povos das minas, para o bem e para o mal, a forma como lidamos e nos apropriamos dos recursos, implicando patrimônio imaterial e material. Seja no alto dos Andes, nos Pirineus, na Chapada Diamantina ou em Diamantina, ou mesmo em Carajás. Da prata ao sal, do diamante ao ferro, a história da evolução humana, dos domínios entre os povos, e da tecnologia, esta marcada e conduzida pelo fazer mineiro e seu desenvolvimento.

O povo que trabalha dentro da Terra, ou é herdeiro destes, compreende ou aprende como poucos a entendê-la, a reverenciá-la, a respeitá-la como força que cria trabalho e possibilidades e também que mata! Uma noção que assusta outros grupos profissionais e populações não mineiras. Sua forma de ser, suas histórias, suas músicas, seus "causos" são moldados pela sua relação com a rocha, o minério, a paisagem, configurando arraigados vínculos com a mineração e patrimônio imaterial.

Não é possível entender em separado este patrimônio. O patrimônio mineiro é um patrimônio misto: material no que diz respeito ao natural que é geológico e paisagístico, histórico no que se traduz industrial e arquitetônico, tecnológico e documental e imaterial tanto cultural como também histórico centrado na memória, na cultura, nas artes e no trabalho, ou seja, na natureza da relação dos grupamentos mineiros e garimpeiros com as rochas.

Assim, apresentar o patrimônio geológicomineiro do Nordeste do Brasil é o objetivo principal desse artigo. Conhecê-lo é de suma importância para protegêlo, pois só se cuida daquilo que se conhece!

\section{PATRIMÔNIO GEOLÓGICO E MINEIRO}

O patrimônio pode ser considerado como bem ou conjunto de bens culturais ou naturais, de valor reconhecido para determinada localidade, região ou país, ou para a humanidade, e que, ao se tornar(em) protegido(s), como por exemplo, pelo tombamento, deve(m) ser protegido(s) para o usufruto de todos os cidadãos. Portanto, o conceito de patrimônio é muito amplo e está associado a uma herança comum, que tem importância para uma dada região, um dado país ou mesmo para toda a humanidade. Os bens culturais e naturais, saberes e modos de fazer pertencem a todos e, portanto, devem ser cuidados para que não se percam.

Integra o patrimônio natural, o patrimônio geológico, que é constituído pelos geossítios (sítios geológicos ou locais de interesse geológico) que registram a memória da história da Terra, num período que alcança milhares, milhões e até bilhões de anos e que incluem (i) afloramentos de rochas; (ii) minerais; (iii) fósseis; (iv) conjuntos de valor paisagístico: serras, montanhas, picos, vales; e (v) coleções de museus de geociências ou de história natural. Porém, quando esses 
elementos da geodiversidade se encontram em um espaço territorial compreendido por atividades de extração, a esse conjunto é dado o nome de patrimônio mineiro. Assim é inegável a forte associação entre esses dois tipos de patrimônios, o geológico e o mineiro, mesmo os mesmos sendo considerados tipos de patrimônios distintos. Para Brilha (2005), dada a diferença de conceitos e metodologias, esses dois termos devem ser mantidos separados.

Um geossítio é considerado a "ocorrência de um ou mais elementos da geodiversidade (aflorantes quer por resultado da ação de processos naturais, quer devido à intervenção do homem), bem delimitado geograficamente e que apresenta valor singular do ponto de vista científico, educativo, cultural, turístico ou outro" (Brilha, 2005).

O conceito de patrimônio geológico está estreitamente relacionado à geodiversidade, contudo este patrimônio não deve ser encarado como sinônimo de geodiversidade, esta sendo a variedade de ambientes geológicos, fenômenos e processos ativos que dão origem a paisagens, rochas, minerais, fósseis, solos e outros depósitos superficiais que são o suporte para a vida na Terra. O patrimônio geológico é apenas uma pequena parcela da geodiversidade, que apresenta características especiais e, por conseguinte, merece/necessita ser conservado.

Assim, o patrimônio geológico é definido como "o conjunto de geossítios inventariados, caracterizados e bem delimitados geograficamente, em uma dada área ou região, onde ocorrem um ou mais elementos da geodiversidade com elevado valor científico, pedagógico, cultural, turístico e outro" (Brilha, 2005; Nascimento et al. 2008).

De acordo com Cortés (1996) esse patrimônio pode ser classificado pelo seu conteúdo em Estratigráfico, Paleontológico, Tectônico, Hidrogeológico, Petrológico, Geotécnico, Mineiro, Mineralógico, Geomorfológico, Geofísico, Geoquímico e Museus e coleções, entre outros. Vale ressaltar aqui que este autor credita o "mineiro" como um tipo de patrimônio geológico.

\section{OS DIFERENTES TIPOS DE PATRIMÔNIO GEOLÓGICO}

Uma das primeiras providências para se desenvolver qualquer atividade ligada a geodiversidade (e, consequentemente, ao seu patrimônio geológicomineiro) é a identificação de aspectos geológicos com particular valor científico, educativo ou turístico. Neste último caso, no nordeste brasileiro, por exemplo, sem dúvida, muitos locais de interesse geológico já eram atrações turísticas antes de os geocientistas os terem estudados. Alguns são verdadeiros cartões-postais, que servem, inclusive, para atrair turistas do exterior, com destaque para Lençóis Maranhenses (MA); Jericoacara e Canoa Quebrada no litoral cearense (CE); Cânion do Rio São Francisco (Al/SE); Morro do Careca e Dunas de Jenipabu (RN), entre muitos outros. O Nordeste, por sua geodiversidade, é detentor de inúmeras feições geológicas que possuem características de patrimônio. A seguir, serão apresentados exemplos de geossítios nas diversas categorias em que o patrimônio geológico pode ser classificado: geomorfológico, paleontológico, espeleológico, sedimentológico, paleoambiental, marinho e tectônico; acrescentando ao final o patrimônio mineiro, este sempre intimamente ligado ao patrimônio geológico.

\subsection{PATRIMÔNIO GEOMORFOLÓGICO}

No Nordeste brasileiro, o relevo se destaca proporcionando paisagens de grande beleza cênica com mirantes que permitem a contemplação dessas áreas, formadas por chapadas, serras, picos, morros e cachoeiras, cujos melhores exemplos são: Chapada Diamantina (BA), Serra da Capivara e Sete Cidades (PI); pico vulcânico do Cabugi (RN), dentre muitos outros.

De forma geral, nesse relevo destacam-se duas categorias de altos topográficos, ambas com sua base constituída por rochas cristalinas (metamórficas e/ou ígneas). Uma categoria possui no topo coberturas sedimentares identificadas pelo topo plano (as conhecidas chapadas). Estas estão representadas pelas serras de Santana, dos Martins e Portalegre (ambas no RN) e pelas chapadas sustentadas por rochas sedimentares, no caso Chapada do Araripe (CE/PE/PB), Chapada do Apodi (RN/CE), Chapada da Ibiapaba (CE/PI) e Chapada Diamantina (BA) (Figuras 1 a 6). Aquelas constituídas unicamente por rochas cristalinas, portanto formadas por litologias ígneas e/ou metamórficas, mostram-se com topo pontiagudo ou irregular. $\mathrm{Na}$ constituição desse relevo, destacam-se as serras, os picos e afloramentos de rochas cujos melhores exemplos são as serras/picos do Cabugi e do Totoró (RN), do Jabre (PB), entre outras. Essas serras e picos são formados principalmente por granitos, basaltos, mármores e gnaisses. Locais como o Morro do Pai Inácio-BA (Pedreira \& Bomfim, 2002), o Parque Nacional de Sete Cidades-PI (Della Favera, 2002), os Eolinitos de Flecheiras/MundaúCE (Carvalho et al. 2009) e a Ponta de Jericoacara-CE (Julio et al. 2012) fazem parte do cadastro de geossítios da Comissão Brasileira de Sítios Geológicos e Paleobiológicos (SIGEP). 


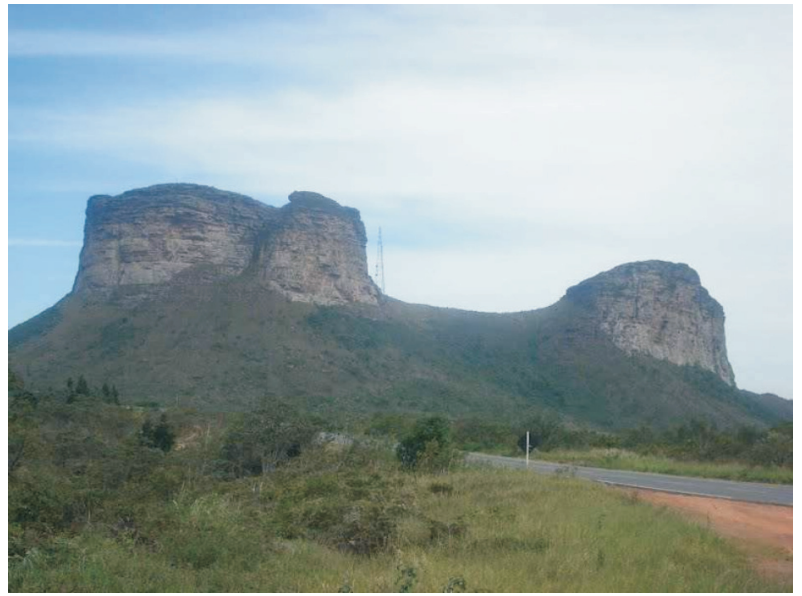

Figura 1 - Exemplo de feições geomorfológicas identificado no Nordeste. Morro do Pai Inácio, Chapada Diamantina (BA).

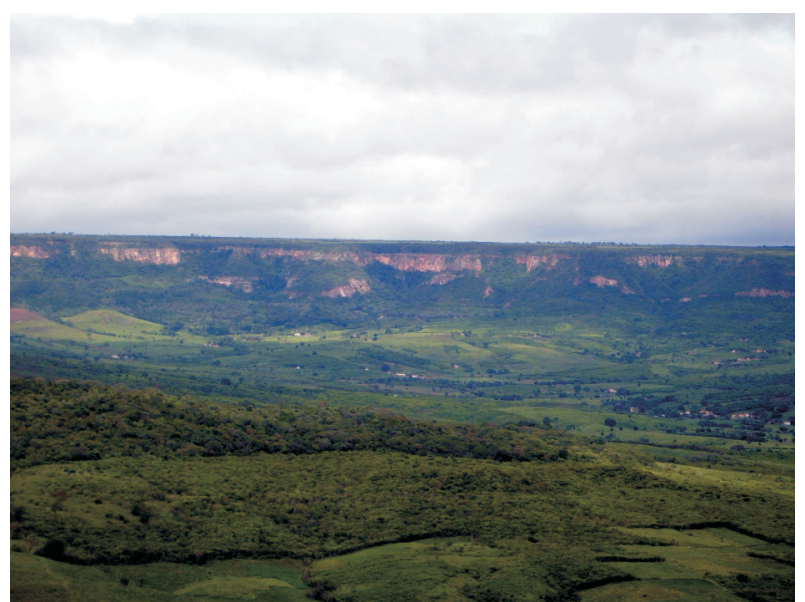

Figura 2 - Exemplo de feições geomorfológicas identificado no Nordeste. Chapada do Araripe (CE).

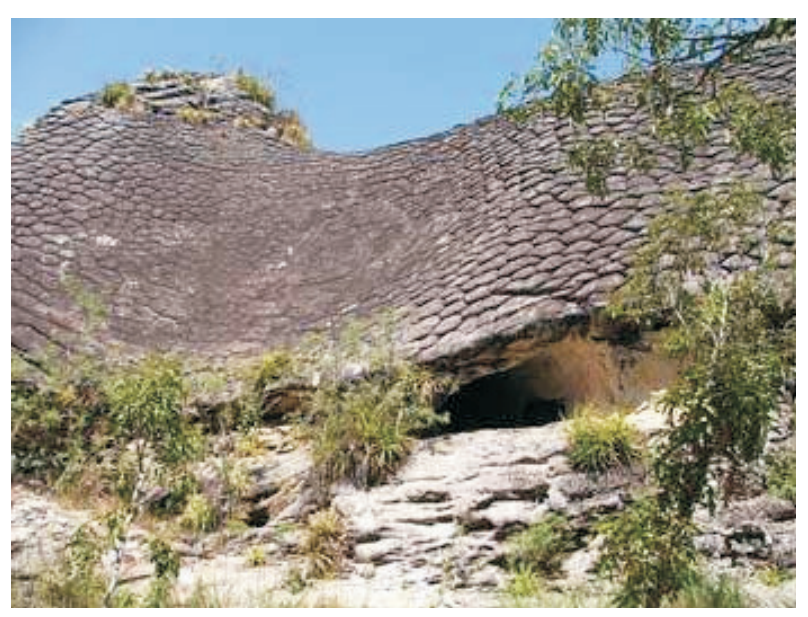

Figura 3 - Exemplo de feições geomorfológicas identificado no Nordeste. Pedra da Tartaruga, Parque Nacional Sete Cidades (PI).

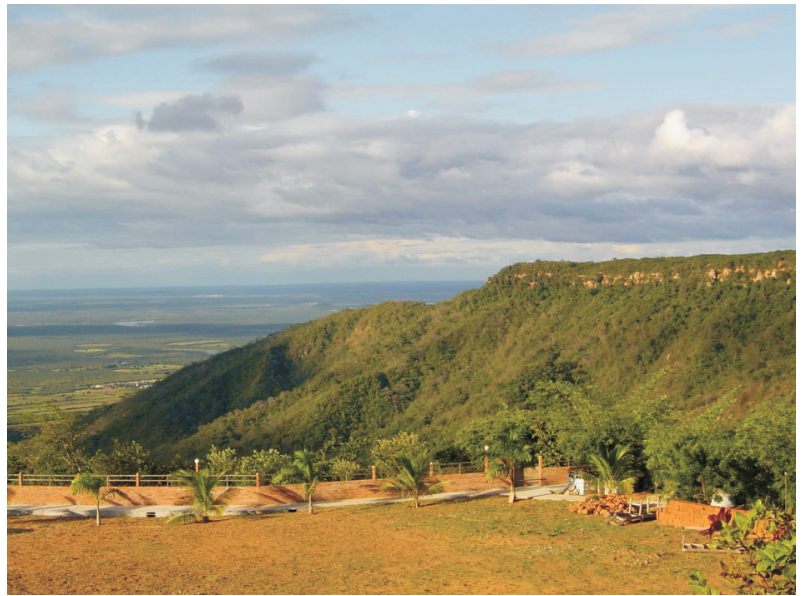

Figura 4 - Exemplo de feições geomorfológicas identificado no Nordeste. Serra de Portalagre (RN).

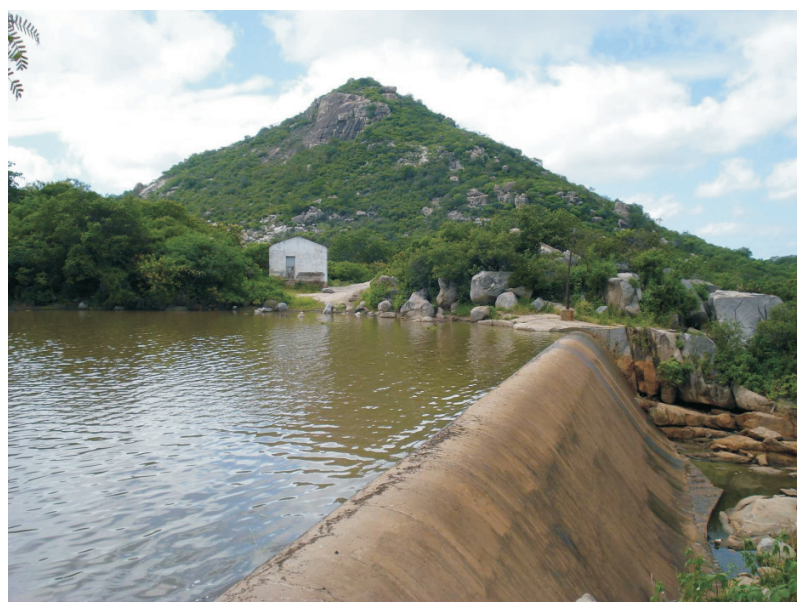

Figura 5 - Exemplo de feições geomorfológicas identificado no Nordeste. Pico do Totoró (RN).

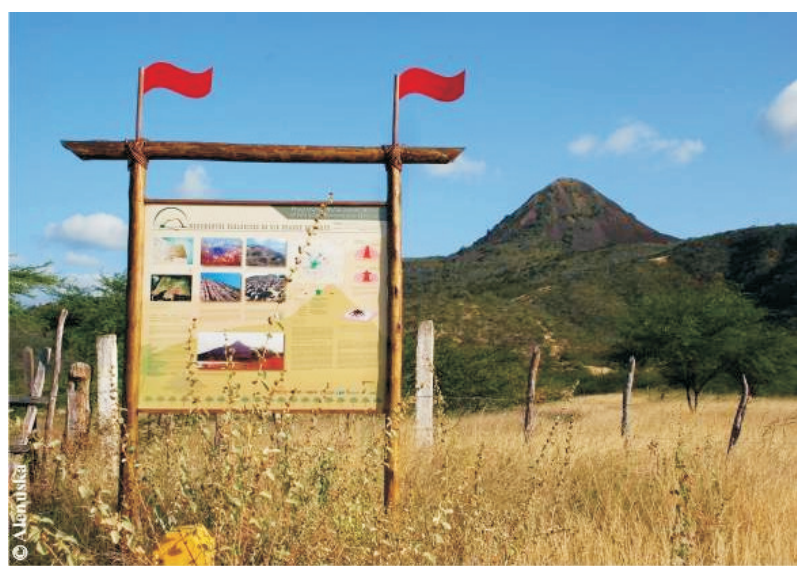

Figura 6 - Exemplo de feições geomorfológicas identificado no Nordeste. Pico do Cabugi (RN). 
A atuação dos processos erosivos, com predomínio de erosão diferencial, juntamente com a atuação dos processos de intemperismo, proporcionam o desgaste da rocha, com a conseqüente formação do cenário atual.

No litoral do Nordeste do Brasil, a paisagem se destaca pela presença de falésias, escarpas costeiras abruptas, muitas vezes não cobertas por vegetação, que se localizam na linha de contato entre a terra e o mar, sendo do tipo ativa ou inativa, especialmente entre os estados do Ceará e da Bahia. A associação desse patrimônio com o patrimônio sedimentológico é bem evidente, em geral, essas paisagens são formadas por arenitos e conglomerados, principalmente da Formação Barreiras. Como alguns exemplos de destaque, têm-se as falésias de Pipa (RN), Ponta Grossa (CE) e Porto Seguro (BA). Outros atrativos paisagísticos do litoral nordestino são as dunas geradas por acumulação de areia depositada pela ação do vento, podendo ser fixas ou móveis. Muitas dessas dunas são consideradas cartõespostais dos lugares onde ocorrem. É o caso das dunas dos Lençóis Maranhenses (MA), do Morro do Careca (RN) e da área da Lagoa do Abaeté em Salvador (BA) (Figuras 7 a 10). Destacam-se ainda os cordões de arenitos encontrados em boa parte do litoral nordestino, descritos como beachrocks (ou arenitos praiais) que servem como substrato rochoso para acúmulos de diferentes tipos de corais. Locais como o Campo de Dunas inativas do médio Rio São Francisco-BA (Barreto et al. 2002), a Costa do Descobrimento do Brasil-BA (Dominguez et al. 2002), o Cânion do Rio Sergi-BA (Pedreira 2002) e os Arrecifes-PE (Barreto et al. 2010) fazem parte do cadastro de geossítios da Comissão Brasileira de Sítios Geológicos e Paleobiológicos (SIGEP).

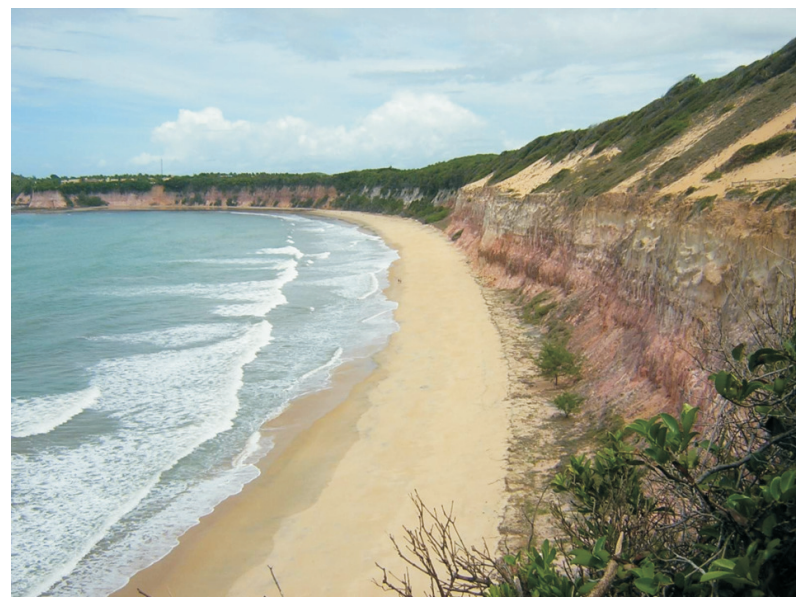

Figura 7 - Exemplo de feições geomorfológicas litorâneas observado no Nordeste. Falésias da Praia de Pipa (RN).

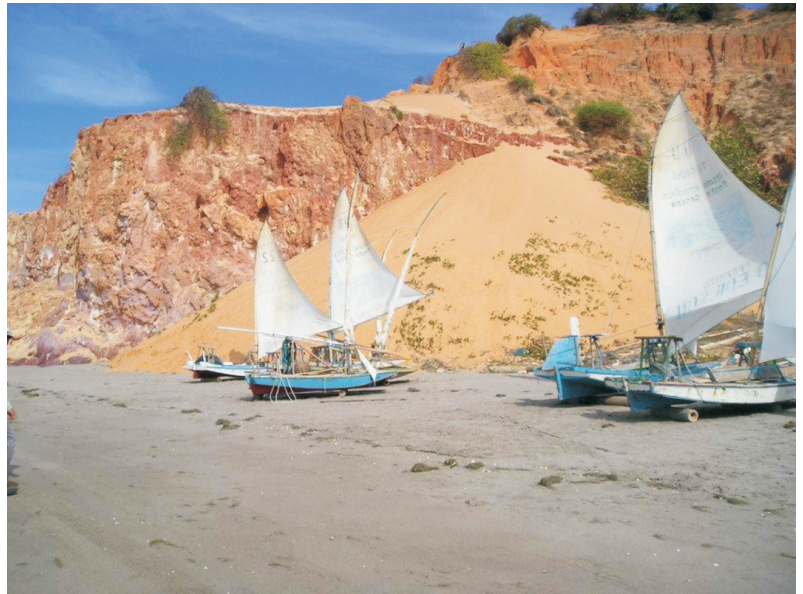

Figura 8 - Exemplo de feições geomorfológicas litorâneas observado no Nordeste. Falésias da Praia de Ponta Grossa (CE).

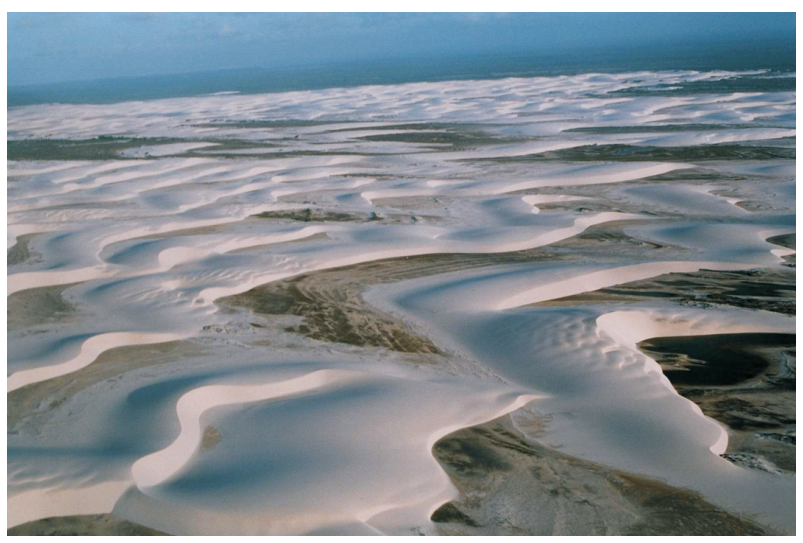

Figura 9 - Exemplo de feições geomorfológicas litorâneas observado no Nordeste. Dunas dos Lençóis Maranhenses (MA).

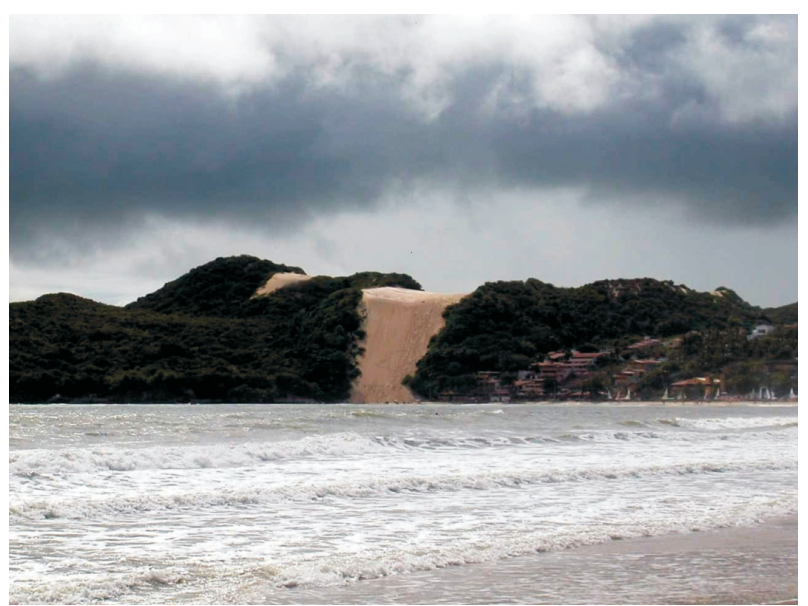

Figura 10 - Exemplo de feições geomorfológicas litorâneas observado no Nordeste. Dunas do Morro do Careca (RN). 
A intenção de utilizar a paisagem (e seu relevo) como atração geoturística, por exemplo, vem da necessidade de cobrir uma lacuna do ponto de vista da informação. A idéia é permitir que o observador (um turista, por exemplo) não só contemple aquelas paisagens, mas também entenda algo sobre os processos geológicos responsáveis por sua formação, o que acarretaria maior valorização do cenário.

\subsection{PATRIMÔNIO PALEONTOLÓGICO}

O fascínio em saber algo sobre o passado da vida na Terra faz com que os locais onde existem esses registros sejam hoje sítios paleontológicos bastante visitados.

No Nordeste, são inúmeros os sítios paleontológicos, destacando-se a Chapada do Araripe (CE-PE), o Vale dos Dinossauros (PB), a rica fauna pleistocênica da Serra da Capivara (PI), os estromatólitos das fazendas Cristal e Arrecife (BA), o Lajedo do Apodi (RN), os tanques fossilíferos de Itapipoca (CE) e São Rafael (RN), entre muitos outros (Figuras 11 a 14). O principal interesse em um sítio paleontológico é a presença de fósseis, que compreendem restos ou vestígios deixados nas rochas por animais e/ou plantas no passado geológico.

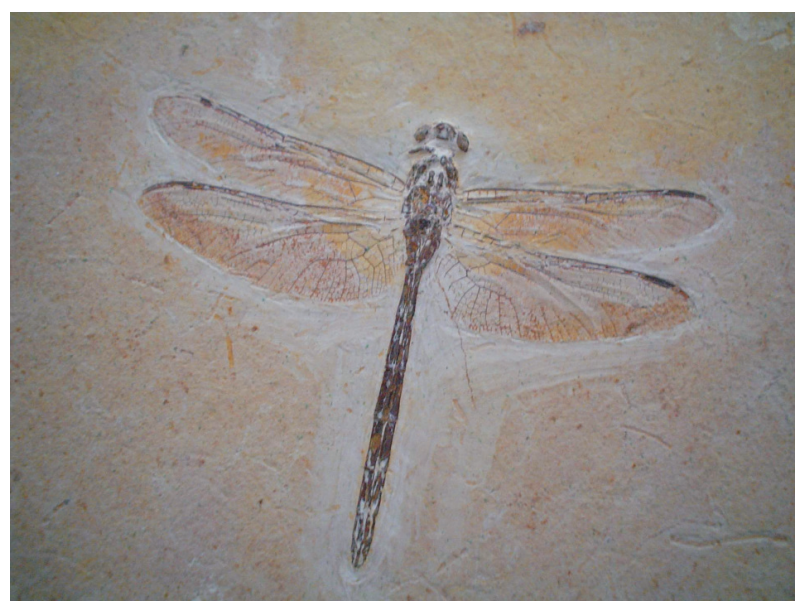

Figura 11 - Exemplo de patrimônio paleontológico no Nordeste. Fóssil de inseto libélula (símbolo do Museu de Paleontologia de Santana do Cariri, CE).

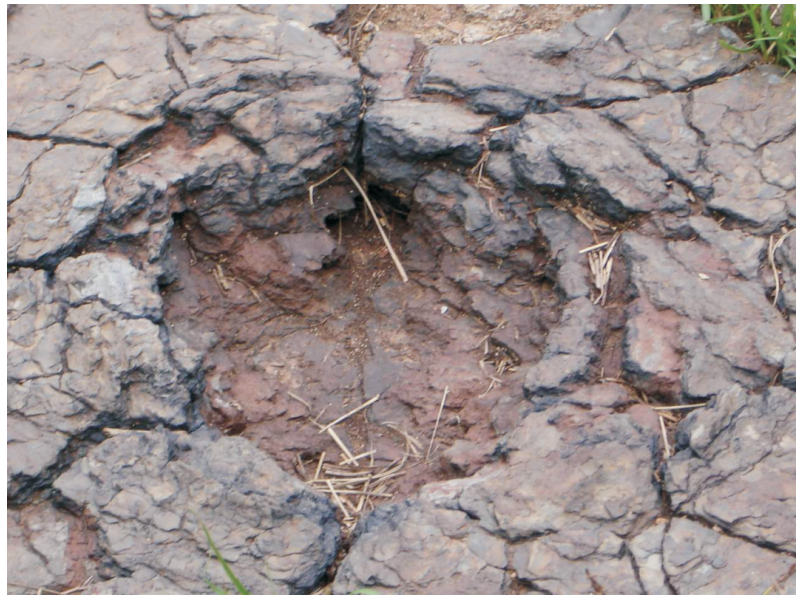

Figura 12 - Exemplo de patrimônio paleontológico no Nordeste. Pegada de dinossauro no Vale dos Dinossauros em Sousa (PB).

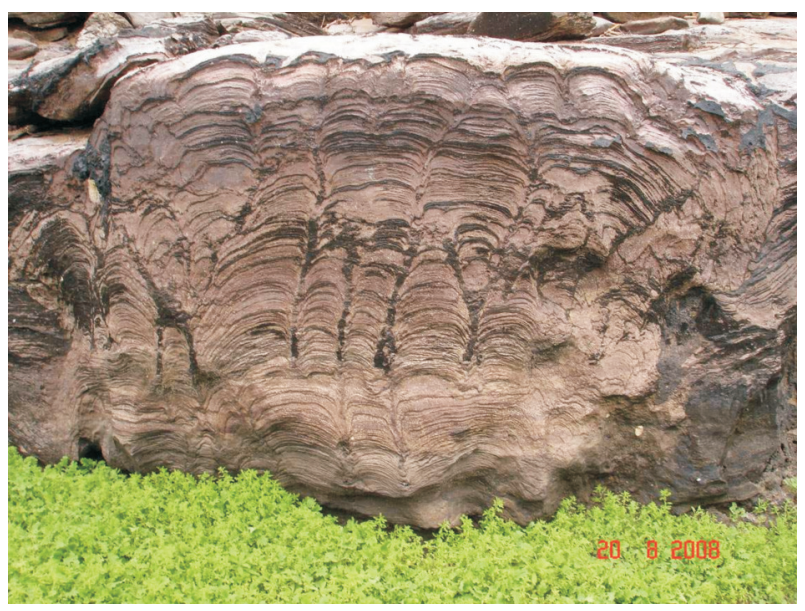

Figura 13 - Exemplo de patrimônio paleontológico no Nordeste. Estromatólito na Fazenda Arrecife (BA).

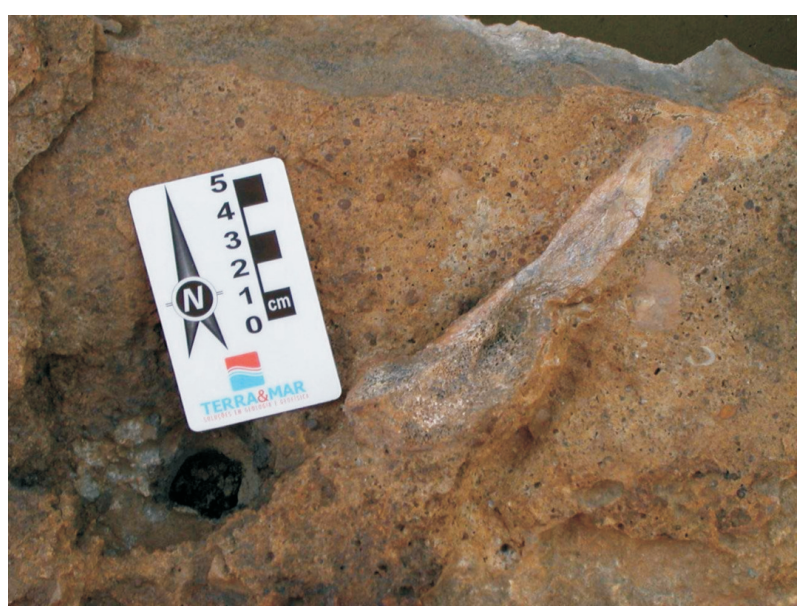

Figura 14 - Exemplo de patrimônio paleontológico no Nordeste. Fóssil de megafauna no Lajedo de Soledade (RN). 
Um excelente exemplo de sítios paleontológicos no Nordeste brasileiro está no Geoparque Araripe, primeiro geoparque nacional com reconhecimento da Rede Global de Geoparques sob os auspícios da UNESCO. Provavelmente, a região é a mais rica em depósitos de vertebrados fósseis do Brasil e um dos mais importantes do mundo, chamando a atenção pelo excelente estado de preservação. É de lá a origem dos milhares de fósseis de peixes encontrados nas feiras e lojas por todo o Brasil - vale salientar que o comércio de fósseis é crime. No geoparque, ocorrem fósseis de dinossauros (mais raros), bem como de peixes, tartarugas, crocodilianos, pterossauros, foraminíferos, crustáceos, gastrópodes, ostracóides, bivalves e equinóides. A região oferece uma possibilidade única para se compreender parte importante do passado geológico e da vida na Terra.

Em muitos sítios paleontológicos são encontradas também artes rupestres (pinturas e gravuras) representando aspectos do dia-a-dia, danças, ritos e cerimônias dos antigos habitantes da região, além de figuras de animais, alguns já extintos. Essas artes préhistóricas, com idades que variam de 2 a 12 mil anos, estão gravadas em paredões de rochas. Vale salientar que, muitas vezes, as artes rupestres fazem parte dos sítios paleontológicos; todavia, estas são consideradas patrimônio cultural e protegidas pelo Instituto do Patrimônio Histórico e Artístico Nacional (IPHAN) e, portanto, enquadram-se no patrimônio cultural.

Outros sítios paleontológicos do nordeste estão cadastrados junto a Comissão Brasileira de Sítios Geológicos e Paleobiológicos (SIGEP), são eles: Fazendo Cristal-BA (Srivastava \& Rocha 2002a), Fazendo ArrecifeBA (Srivastava \& Rocha 2002b), Icnofósseis da Bacia do Rio do Peixe-PB (Leonardi \& Carvalho 2002), Membro Crato da Formação Santana-CE (Viana \& Neumann 2002), Membro Romualdo da Formação Santana (Kellner 2002), Toca da Janela da Barra do Antonião-PI (Guerin et al. 2002), Lajedo de Soledade-RN (Porpino et al. 2009), Tanques Fossilíferos de Itapipoca-CE (Ximenes 2009) e Afloramento Fossilífero de Oiti-PI (Pociano et al. 2010).

\subsection{PATRIMÔNIO ESPELEOLÓGICO}

Esse tipo de patrimônio se refere às cavernas que se desenvolvem, principalmente, em calcários e mármores, embora ocorram também em formações ferríferas bandadas, arenitos, quartzitos e granitos. Esse tipo de relevo apresenta um conjunto de feições muito características que, além das próprias cavernas, configuram uma grande beleza cênica, como maciços rochosos expostos, paredões ou escarpas, vales, torres, depressões, dolinas, lagoas, além dos espeleotemas (estalactites, estalagmites, bolo de noiva, etc).

Segundo Auler \& Zogbi (2005), o Nordeste é uma região favorável à descoberta de novas grutas. $\mathrm{Na}$ Bahia, por exemplo, destaca-se a Gruta do Padre, com
16,3 km de extensão - terceira maior caverna descoberta no país. As principais cavernas de interesse ocorrem na região da Chapada Diamantina, com várias de grande extensão e beleza, como a Lapa Doce. Registra-se, ainda, a região de Campo Formoso, que apresenta as duas maiores cavernas do país: Toca da Boa Vista (Auler \& Smart, 2002) e Toca da Barriguda, com 105 km e 32 km de extensão, respectivamente. No município de Morro do Chapéu existem a Gruta dos Brejões com $7 \mathrm{~km}$ de extensão, com grande diversidade de espeleotemas, e a caverna do Cristal, com cerca $4 \mathrm{~km}$ de extensão, praticamente desprovida de espeleotemas, embora com potencial paleontológico (Figuras 15 e 16).

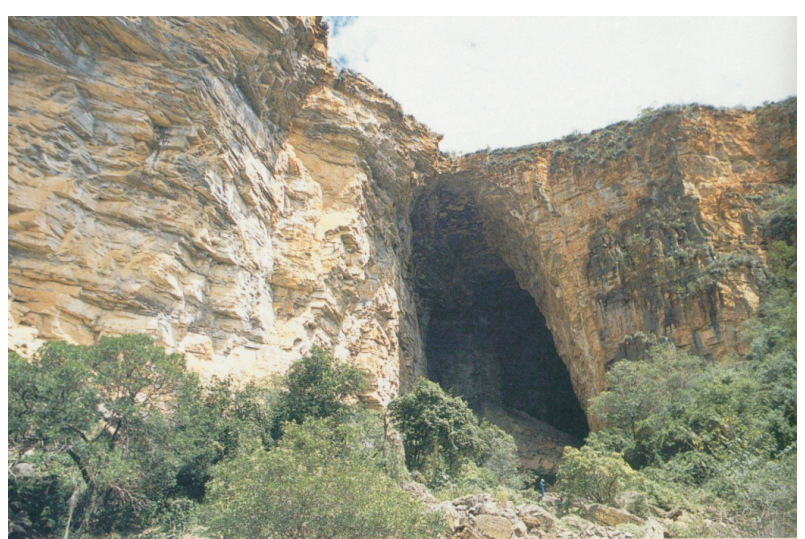

Figura 15 - Exemplo de patrimônio espeleológico no Nordeste. Gruta dos Brejões (BA), formada em calcários.

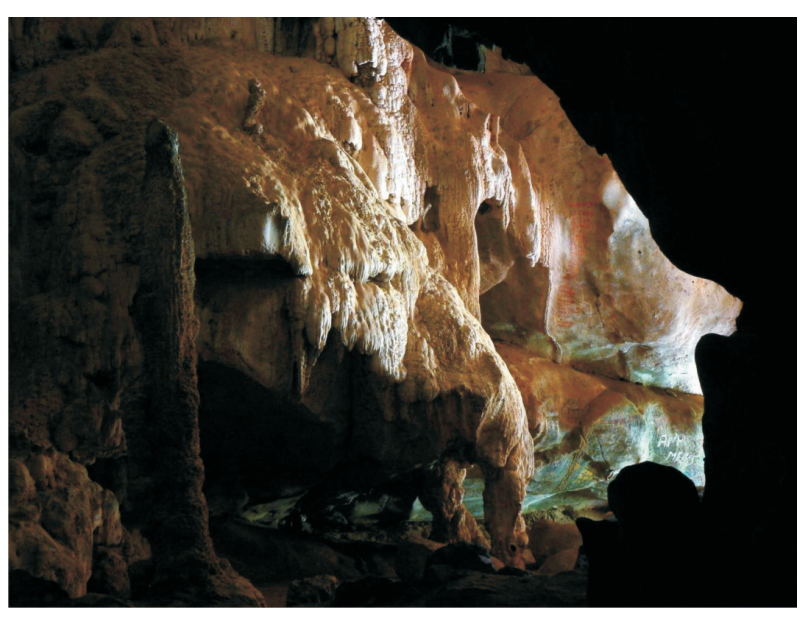

Figura 16 - Exemplo de patrimônio espeleológico no Nordeste. Casa de Pedra de Martins (RN), formada em mármore. 
No Ceará, uma das mais conhecidas é a Gruta de Ubajara, um dos parques nacionais mais antigos do Brasil. No Rio Grande do Norte, a região entre Felipe Guerra e Apodi concentra a maior quantidade de cavernas, com destaque para a Casa de Pedra de Martins, considerada a segunda maior caverna em mármore do Brasil.

Muitas cavernas no Nordeste já são consideradas de uso turístico. Esse tipo de geoturismo, também denominado "turismo espeleológico" (ou espeleoturismo), é a prática puramente esportiva e recreativa de visitação às cavernas, mas que deve ser realizada com o auxílio de especialistas. Para Auler \& Zogbi (2005), a abertura de uma caverna para o turismo em massa provoca uma série de intervenções que podem vir a alterar ou mesmo danificar permanentemente a caverna. A instalação de luz artificial, por exemplo, pode levar à alteração da temperatura e da umidade da caverna. Uma das cavernas mais impactadas pela adaptação para o turismo é a Furna dos Morcegos (SE), próxima a Paulo Afonso (BA). Nessa gruta, a escavação de um elevador na rocha e a construção de um enorme chafariz descaracterizaram irreversivelmente o ambiente da caverna.

Na lista dos sítios espeleológicos cadastrados na Comissão Brasileira de Sítios Geológicos e Paleobiológicos (SIGEP) estão a Toca da Boa Vista-BA (Auler \& Smart 2002), as Grutas de Iraquara-BA (Laureano \& Cruz Jr. 2002), a Lapa dos Brejões-BA (Berbert-Born \& Karmann 2002) e o Poço Encantado-BA (Karmann et al. 2002).

\subsection{PATRIMÔNIO PALEOAMBIENTAL}

Os paleoambientes correspondem aos ambientes antigos em que ocorreu a formação das rochas. A reconstituição dos paleoambientes exige 0 estudo das fácies, características litológicas e paleontológicas das formações geológicas, que permitem compreender e interpretar o ambiente existente quando o estrato sedimentar se formou.

No Nordeste brasileiro alguns geossítios, inclusive cadastrados na Comissão Brasileira de Sítios Geológicos e Paleobiológicos (SIGEP), são considerados patrimônio paleoambiental, como é o caso das serras do Tombador (Pedreira \& Rocha 2002) e do Sincorá (Pedreira 2002), ambas na Chapada Diamantina (BA), sendo a primeira um belo registro de um deserto antigo e, a segunda, exemplo de paleopláceres de diamante com beleza paisagística. Os calcários da Pedreira Poty (PE) (Albertão \& Martins Jr. 2009) mostram evidências de um evento catastrófico no primeiro registro do limite $\mathrm{K}-\mathrm{T}$ descrito na América do Sul, enquanto na região de Brejo do Piauí (PI) são descritos pavimentos estriados (Caputo \& Ponciano 2010), registrando geleiras continentais com cerca de 360 milhões de anos (Figuras 17 e 18).

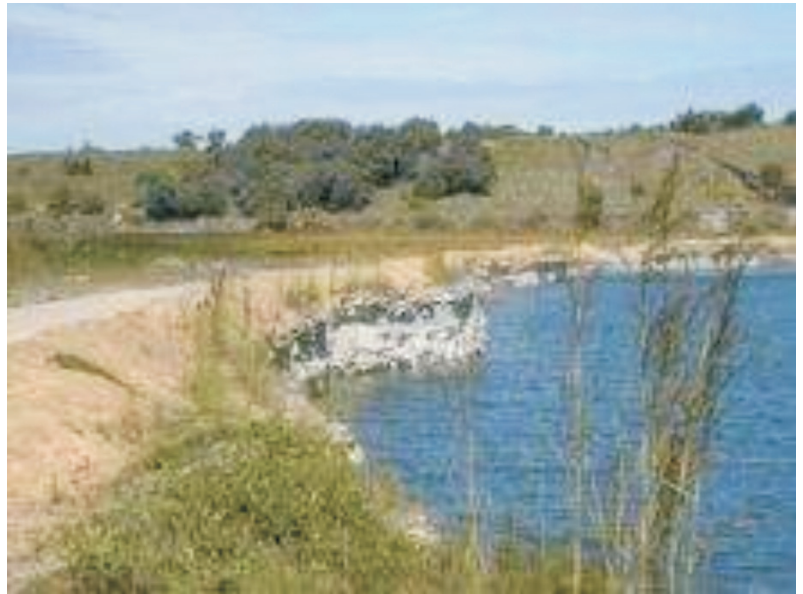

Figura 17 - Exemplo de patrimônio paleoambiental no Nordeste. Calcários da Pedreira Poty (PE) onde ocorre registro do limite K-T.

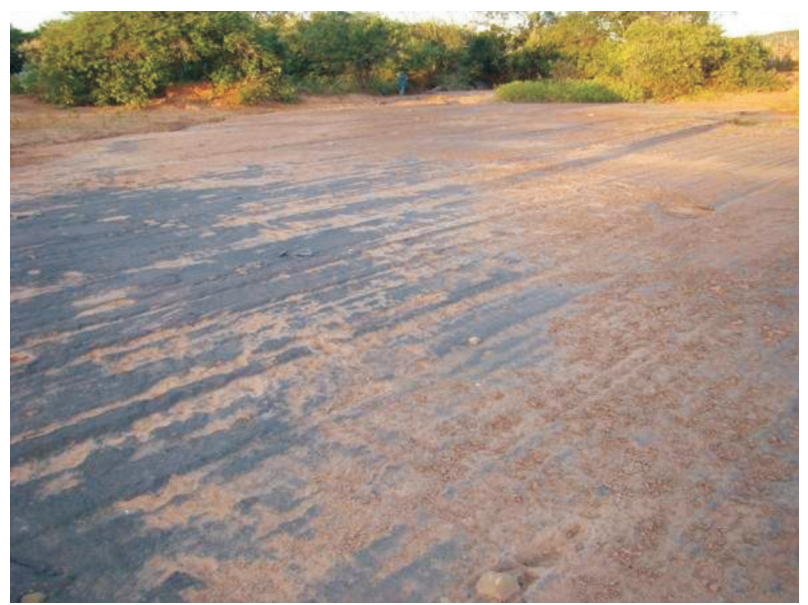

Figura 18 - Exemplo de patrimônio paleoambiental no Nordeste. Pavimentos estriados na região de Brejo do Piauí (PI) evidenciando antiga geleira.

\subsection{PATRIMÔNIOTECTÔNICO}

Esse tipo de patrimônio está ligado a qualquer processo geológico em que se tem movimentação ou deslocamento de massas rochosas, construindo ou reorganizando a estrutura terrestre devido a tensões crustais, por exemplo, orogênese, epirogênese, falhamentos, diapirismo, etc.

Assim, feições estruturais ímpares impressas sobre as rochas podem ser identificadas como patrimônio, a exemplo das importantes deformações tectônicas cenozóicas observadas em rochas sedimentares da Formação Barreiras nas falésias na Praia de Ponta Grossa (CE) (Sousa et al. 2009), já cadastrada na lista da Comissão Brasileira de Sítios Geológicos e Paleobiológicos (SIGEP), bem como a Falha Geológica de Salvador (BA), esta caracterizando o desnível existente entra a Cidade Alta e a Cidade Baixa da capital da Bahia. Olhando em direção ao Elevador Lacerda, observa-se 
ao fundo um paredão de rocha. Essa escarpa que une a Cidade Alta e a Cidade Baixa - incluindo toda a faixa esverdeada pela vegetação - define o Plano da Falha Geológica de Salvador (Figuras 19 e 20).

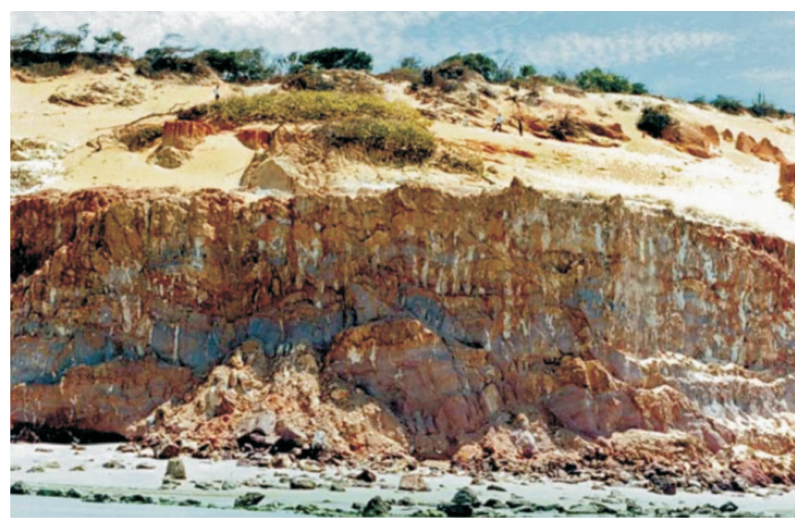

Figura 19 - Exemplo de patrimônio tectônico no Nordeste. Falésias na Praia de Ponta Grossa (CE).

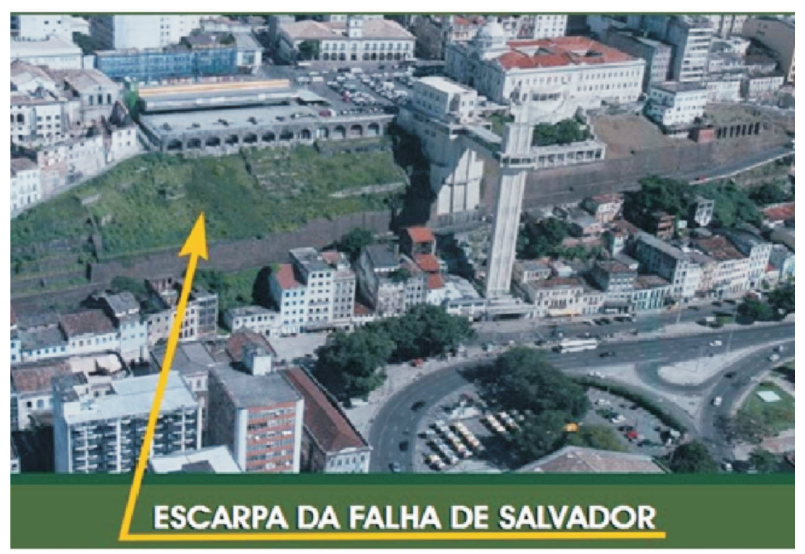

Figura 20 - Exemplo de patrimônio tectônico no Nordeste. Escarpa de Falha na cidade de Salvador (BA).

\section{ESTÁGIO ATUAL DE IDENTIFICAÇÃO DE GEOSSÍTIOS NO NORDESTE}

A região nordeste do Brasil possui uma grande diversificação litológica, com ampla distribuição ao longo da escala de tempo geológico. Este fato implica em uma responsabilidade da comunidade local com a preservação dos geossítios que constituem patrimônio geológico desta região. Essa responsabilidade deve ser compartilhada pelos geólogos e demais profissionais que atuam na área, entidades de classe, órgãos públicos e empresas particulares, além das universidades.

Neste sentido, o passo inicial seria decidir o que deve ser protegido. Essa decisão exige a realização de um inventário amplo (estadual, por exemplo) sistemático de geossítios, que poderia ser desenvolvido tendo como base as unidade litológicas, na escala 1:250.000, que constam do GEOBANK (Banco de Dados) da CPRM.

Em um levantamento realizado para a região nordeste chegou-se a 164 geossítios identificados, embora vários ainda não possuam a respectiva descrição e, inclusive, em alguns casos as coordenadas não estejam disponíveis (Figura 21). Para tal levantamento lançou-se mão de fontes bibliográficas (Figura 22), descritas abaixo:

- 19 geossítios - Schobbenhaus et al 2002;

- 08 geossítios - Winge et al 2009;

- 03 geossítios - Wing et al (no prelo);

- 14 geossítios - Já aprovados pela SIGEP;

- 47 geossítios - Cadastrados no aplicativo GEOSSIT desenvolvido pela CPRM;

- 25 geossítios Dsiponibilidados na Tese de Doutorado de Pereira (2010);

- 48 geossítios - Schobbenhaus \& Silva 2012.

\section{Total de Geossítios}

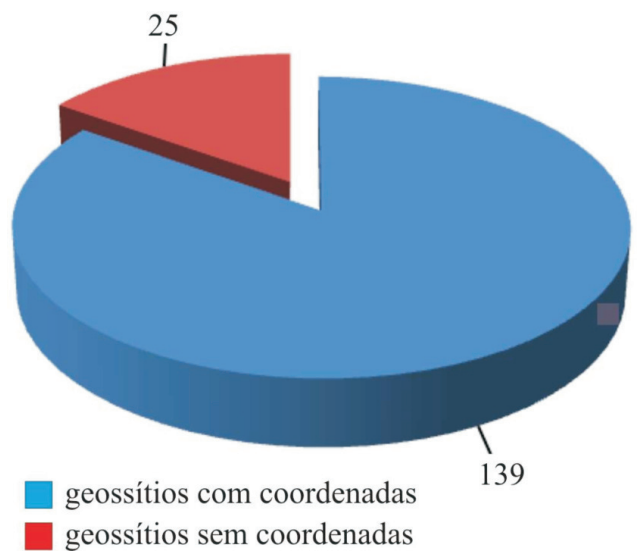

Figura 21 - Total de geossítios identificados na região nordeste (dados de Abril de 2013).

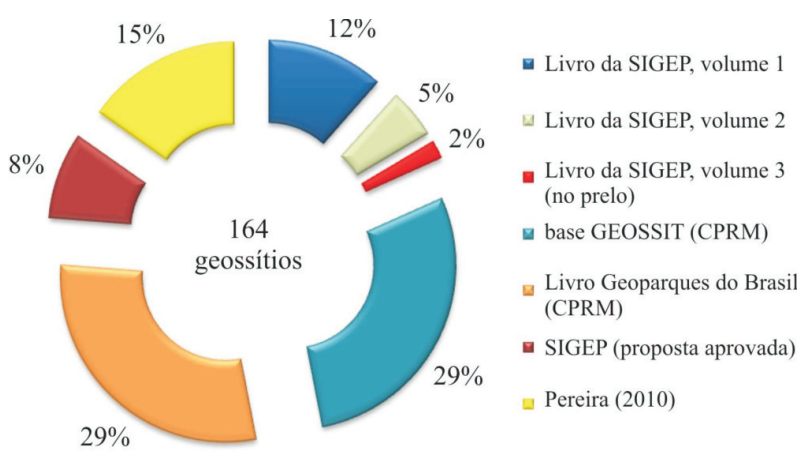

Figura 22 - Fontes consultadas para identificação dos geossítios na região nordeste. 
A análise por estados mostra a Bahia com o maior número de geossítios identificados (Figuras $23 \mathrm{e}$ 24). No outro extremo está o estado de Alagoas, com um geossítio identificado. Esta situação decorre, provavelmente, no primeiro caso da presença de universidade, unidade regional da CPRM, órgão estadual com atuação no setor mineral ou tradição de pesquisa em algum campo da geologia, a exemplo da paleontologia. E, no segundo caso do fato de não existir um curso de geologia no estado, nem a presença de uma Superintendência ou Núcleo da CPRM em Maceió.

De uma maneira geral o atual cenário de identificação de geossítios reflete também a ação individual de alguns pesquisadores, bem como o fato de que algumas instituições já se mostram receptivas ao assunto.

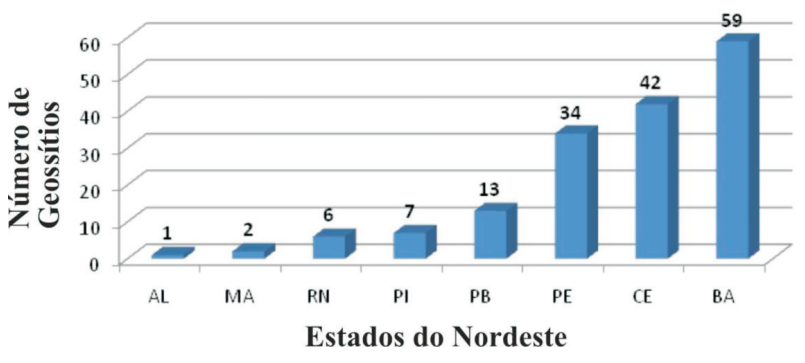

Figura 23 - Distribuição da quantidade de geossítios por estados no nordeste.

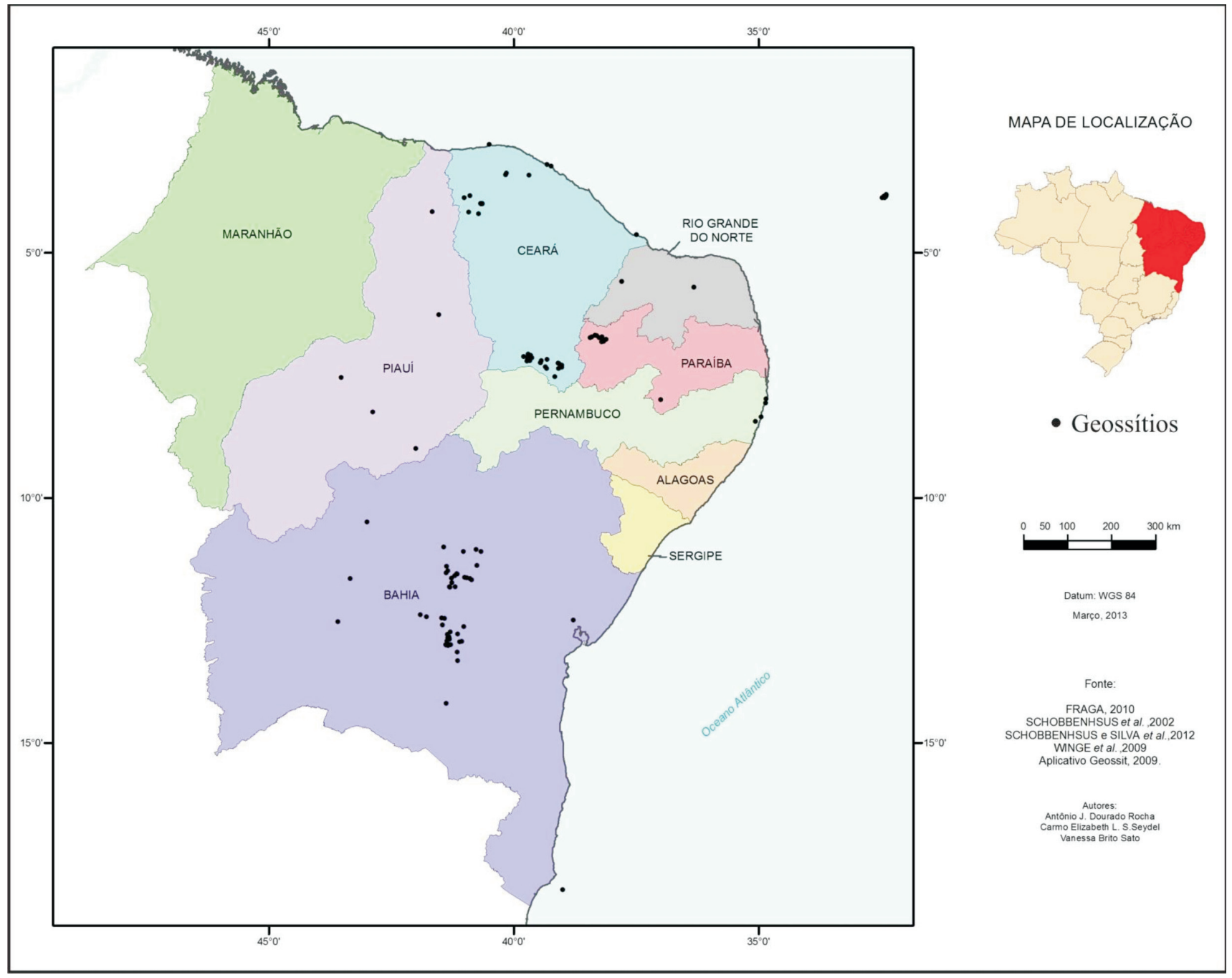

Figura 24-Distribuição dos geossítios por estados no nordeste. 
Os geossítios identificados estão distribuídos em 14 categorias temáticas, com destaque para a sedimentologia, paleontologia e geomorfologia (Figura 25).

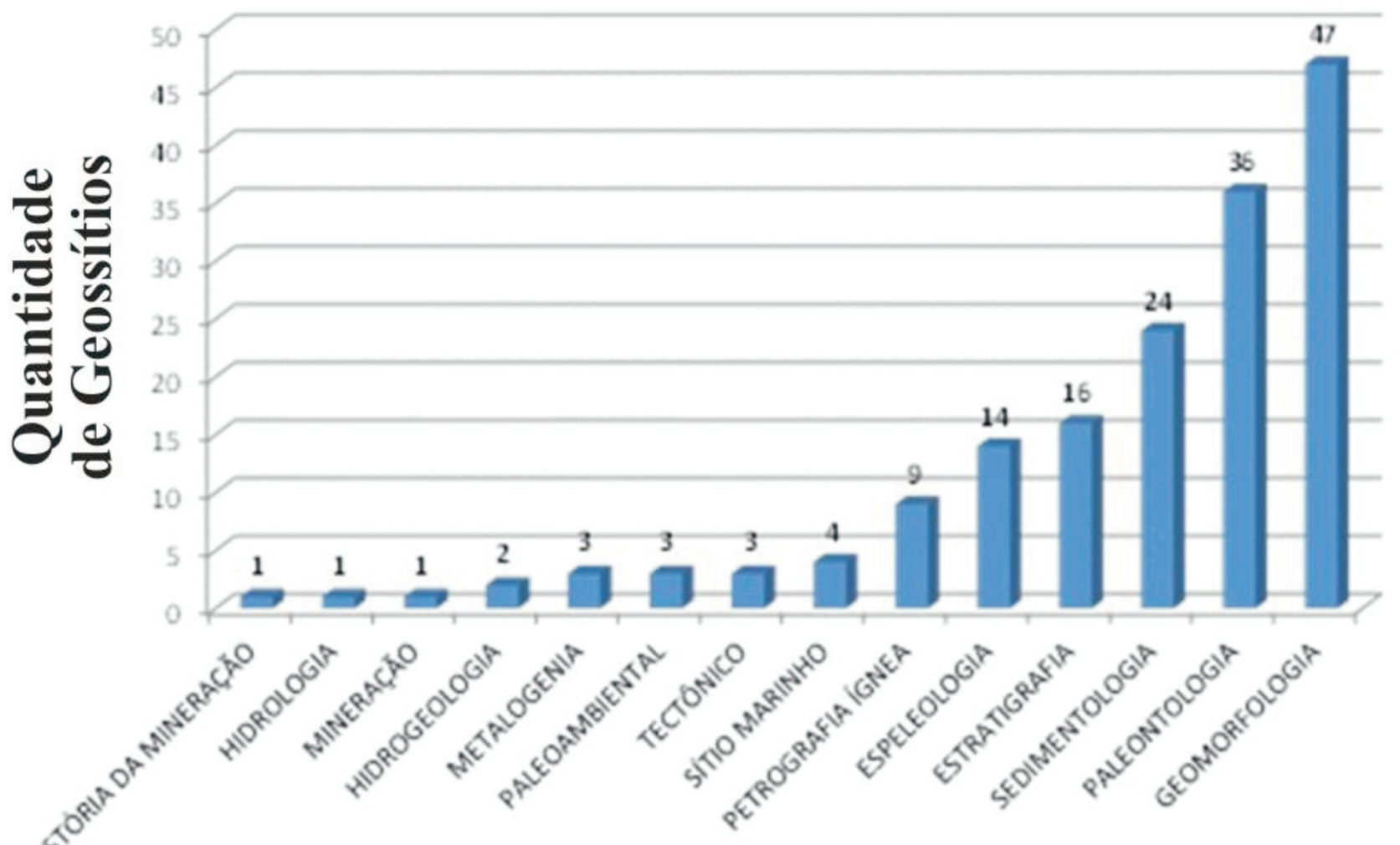

\section{Categoria Temática}

Figura 25 - Classificação temática para os geossítios encontrados no nordeste.

O cenário atual relativo ao número de geossítios, distribuição por estados e número de classes temáticas, deverá ter alterações profundas, na medida em que sejam implementados os cadastramentos estaduais. Esse cadastramento pode ser conduzido pelos estados, de acordo com uma sistemática a ser estabelecida, ou mesmo venha ser realizado pela CPRM. Neste último caso teríamos 3 cenários distintos (Tabela 1):

\begin{tabular}{|c|c|c|c|}
\hline Projetos & Características do Geossítio & Vantagens & Desvantagens \\
\hline Em desenvolvimento & $\begin{array}{c}\text { Ao final dos trabalhos o chefe } \\
\text { do projeto indica os } \\
\text { geossítios. }\end{array}$ & $\begin{array}{l}\text { Baixo custo. Respostas a } \\
\text { curto e/ou médio prazo. }\end{array}$ & \\
\hline Concluído & $\begin{array}{l}\text { O geólogo que foi o chefe do } \\
\text { projeto indica os geossítios. }\end{array}$ & $\begin{array}{l}\text { Baixo custo. Respostas a } \\
\text { curto e/ou médio prazo. }\end{array}$ & $\begin{array}{l}\text { A equipe do projeto pode } \\
\text { não mais pertencer aos } \\
\text { quadros da empresa. }\end{array}$ \\
\hline A ser iniciado & $\begin{array}{c}\text { Ao final dos trabalhos o chefe } \\
\text { do projeto indica os } \\
\text { geossítios. }\end{array}$ & $\begin{array}{c}\text { Respostas a médio/longo } \\
\text { prazo. }\end{array}$ & $\begin{array}{l}\text { Não é possível prever a data } \\
\text { de conclusão do projeto. }\end{array}$ \\
\hline
\end{tabular}

Tabela 1-Sistemática envolvida no cadastramento de geossítios. 
Em face do tamanho e do grau de dificuldade da tarefa, seguramente a CPRM deverá buscar parceiras, preferencialmente com as universidades, que inclusive já desenvolvem o cadastro em alguns estados do Nordeste.

\section{PATRIMÔNIO MINEIRO}

A mineração apresenta um potencial enorme na divulgação dos elementos da geodiversidade. Essa atividade já é bastante difundida em outros países e, no Nordeste, tem forte potencial ainda a ser explorado.

A Mina Brejuí (Currais Novos - RN), localizada a cerca de 180 km de Natal (RN), na região do Seridó Potiguar, é um exemplo de sucesso no que se refere à adaptação de uma mina para desenvolvimento de atividade geoturística. Ela foi uma das maiores produtoras de scheelita (minério rico em tungstênio) da América do Sul, com sua exploração iniciada em 1943 e tendo seu apogeu durante a Segunda Guerra Mundial. Em 1996, essa mina teve suas atividades paralisadas, retornando a elas no ano de 2005 . No entanto, já a partir de 2000 , as atividades voltadas ao turismo começaram a ser implantadas. Hoje, a mina Brejuí é considerada o maior parque temático do Rio Grande do Norte, sendo visitada diariamente por turistas e estudantes oriundos de todas as regiões do Brasil e do exterior, contabilizando-se mais de 30.000 turistas em visita à mina. Os turistas e estudantes podem desfrutar das riquezas históricas e culturais da mina por meio da visitação aos túneis e galerias, dunas de rejeito, museu mineral e outras atrações (Figura 26 a 29).

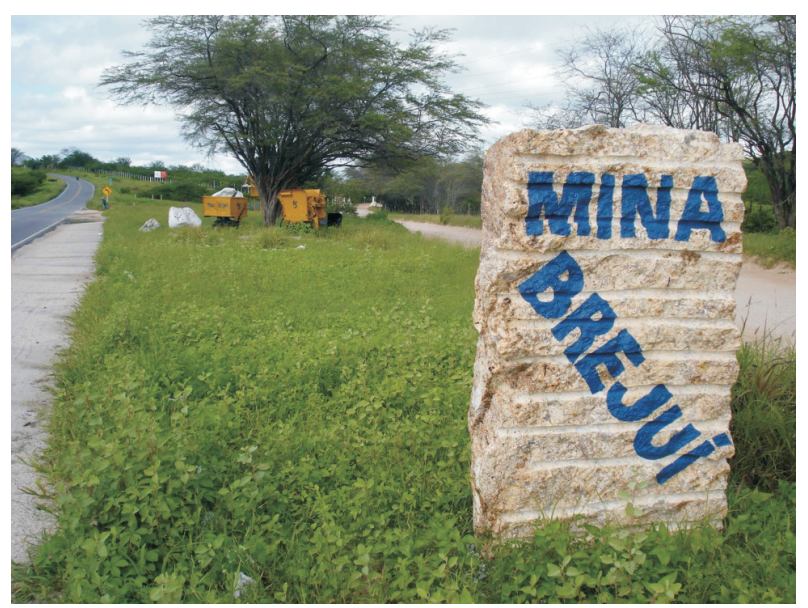

Figura 26 - Exemplo do patrimônio mineiro encontrado na Mina Brejuí (Currais Novos, RN). Entrada com Parque Temático.

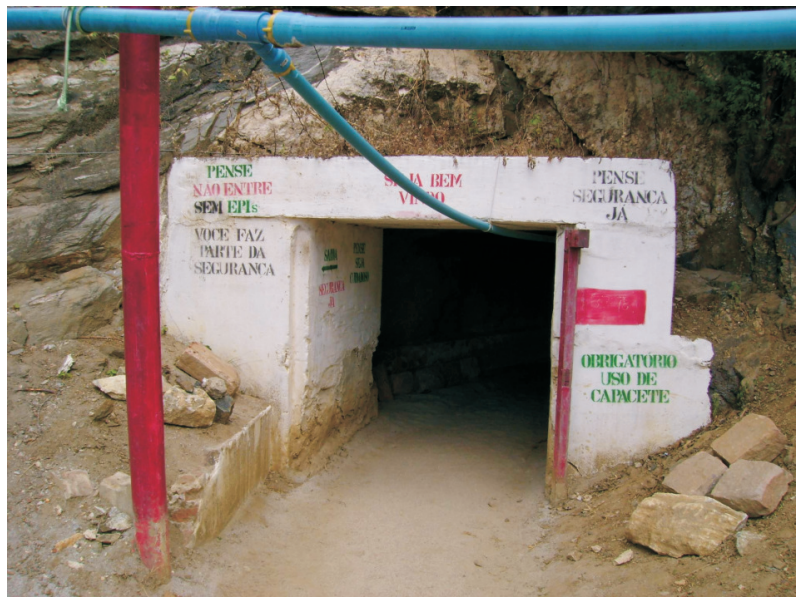

Figura 27 - Exemplo do patrimônio mineiro encontrado na Mina Brejuí (Currais Novos, RN). Entrada do túnel preparado para visitação (Galeria Fernando, nível 3378).

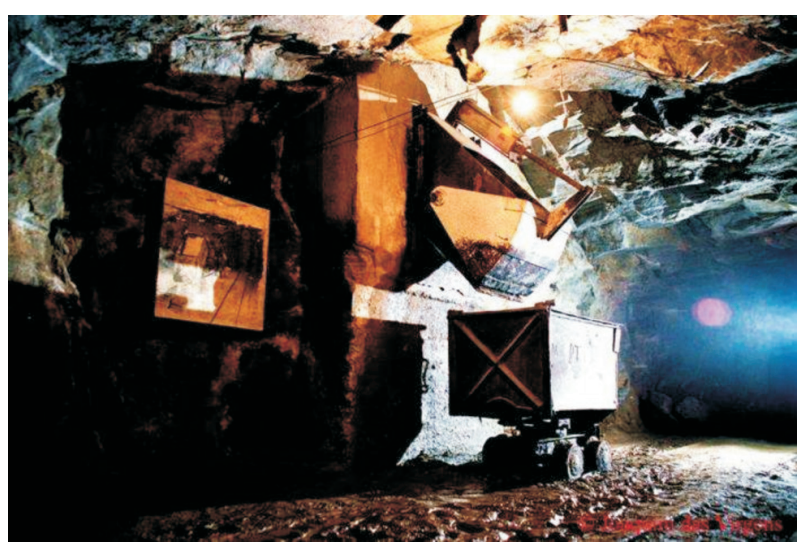

Figura 28 - Exemplo do patrimônio mineiro encontrado na Mina Brejuí (Currais Novos, RN). Bica e vagonete utilizados para descida e retirada do minério.

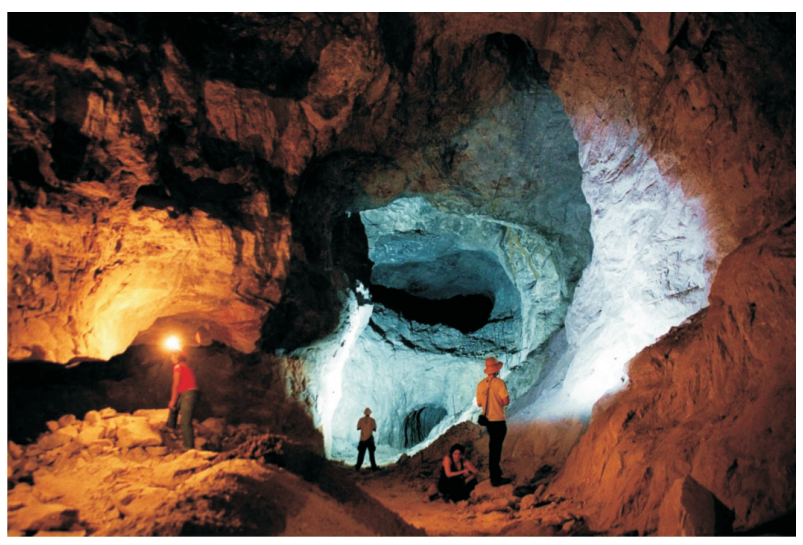

Figura 29 - Exemplo do patrimônio mineiro encontrado na Mina Brejuí (Currais Novos, RN). Um dos salões visitados dentro da Mina Brejuí. 
Outra estratégia importante é criar roteiros que integrem minas e garimpos, assim valorizando e preservando esse rico patrimônio mineiro. Um exemplo desse tipo de roteiro foi publicado por Liccardo \& Nascimento (2008) sendo definido como "Roteiro de Turismo Mineral no Nordeste" (Figuras 30 a 32). Neste, o passado e o presente registram a história, a identidade e a cultura da região associada aos diferentes recursos minerais encontrados em minas e garimpos. O conhecimento geocientífico disponibilizado neste roteiro valoriza o patrimônio geológico-mineiro, tornando-o acessível às comunidades locais e aos visitantes.

Esse roteiro é apresentado em consonância com atrativos turísticos tradicionais, unindo quatro estados do Nordeste e dois pólos de entrada do turismo internacional (Natal/RN e Fortaleza/CE). Integra ainda produção com potenciais consumidores. O trajeto proposto parte de Natal/RN e termina em Fortaleza/CE, mas pode ser utilizado em ambos os sentidos. Ao longo desta rota são considerados os principais pólos com as seguintes localidades: Natal/RN; Lajes Pintadas/RN com produção de água-marinha e esmeralda, além de minerais de coleção ligados aos pegmatitos e pedrasabão; Currais Novos/RN com a famosa Mina Brejuí (scheelita), já transformada em atração turística, e um núcleo de artesanato mineral e lapidação; Carnaúba dos Dantas/RN com quartzo rosa, espessartita e berilo; Parelhas/RN com turmalinas verdes, azuis e vermelhas, água-marinha, heliodoro e outros; Equador/RN com raríssimos euclásios azuis; Junco do Seridó/PB com a única produção mundial de turmalina-da-Paraíba, material que alcança preços de até 100 mil dólares por grama e uma profusão de rochas ornamentais; Campina Grande/PB com o Centro Gemológico do Nordeste; Souza/PB, importante sítio paleontológico/arqueológico dentro do trajeto, com as pegadas de dinossauros; Tenente Ananias/RN com água-marinha e esmeralda; Solonópole/CE com turmalina e água-marinha; Quixeramobim/CE que produz berilo em seu entorno e é um pólo de desenvolvimento de joalheria e aproveitamento de materiais; Pedro II/PI com a segunda maior produção mundial de opala nobre, associada à Bacia Sedimentar do Parnaíba, e um forte núcleo de artesanato mineral e joalheria; Buriti dos Montes/PI que apresenta produção inicial de opala-de-fogo, também ligada às rochas sedimentares. Este roteiro apresenta uma série de atrativos geoturísticos ligados à paisagem do sertão, propondo uma verdadeira interação do intenso turismo que acontece no litoral com o interior destes estados.

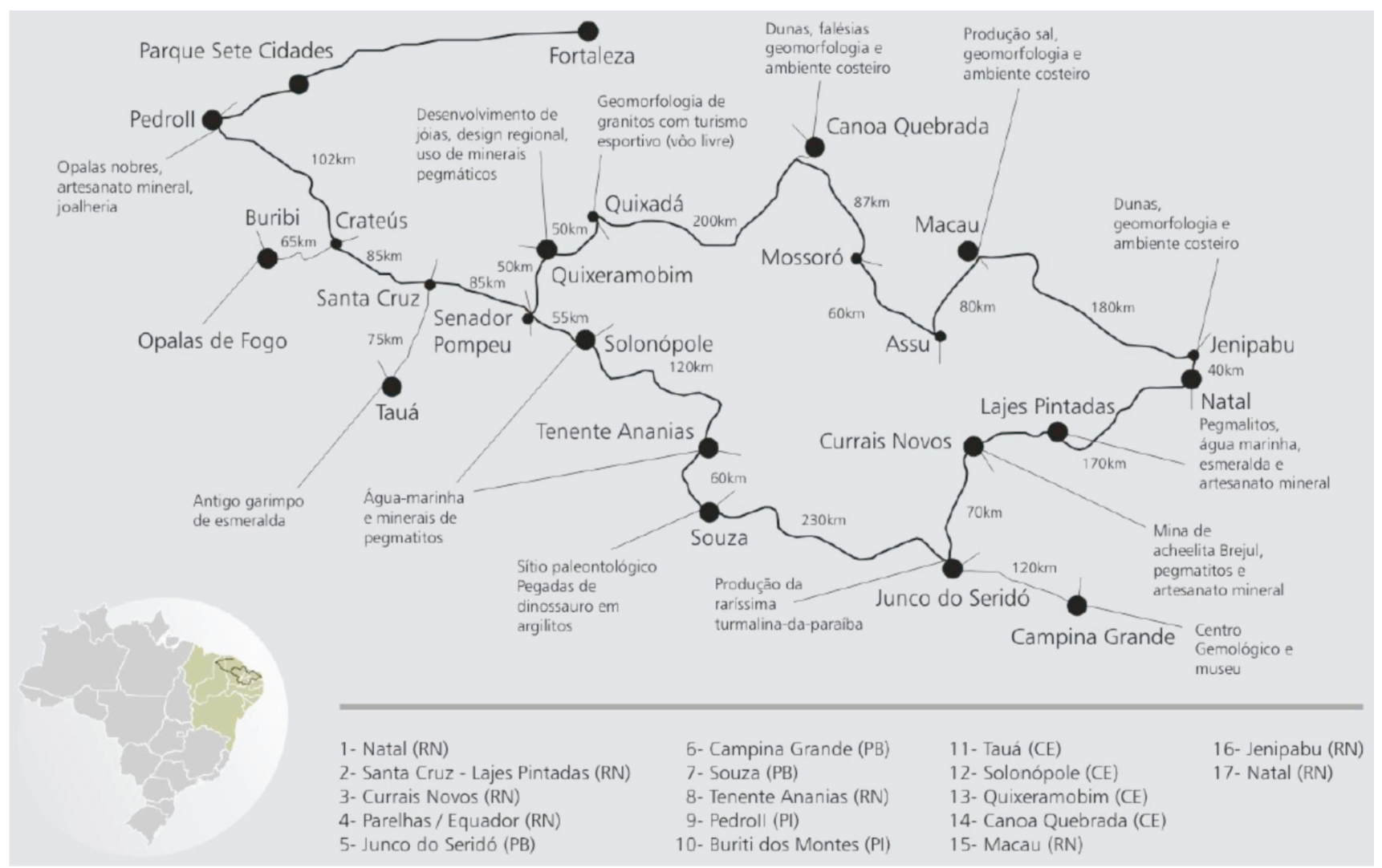

Figura 30-Uso de minas e garimpos em roteiro de turismo mineral. Mapa do Roteiro de Turismo Mineral no Nordeste. 


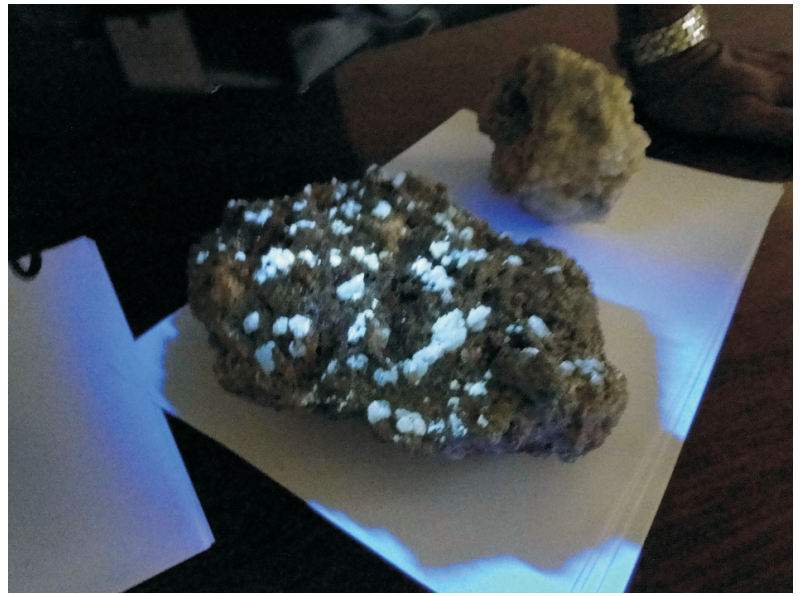

Figura 31 - Uso de minas e garimpos em roteiro de turismo mineral. Fluorescência em scheelita da Mina Brejuí (RN).

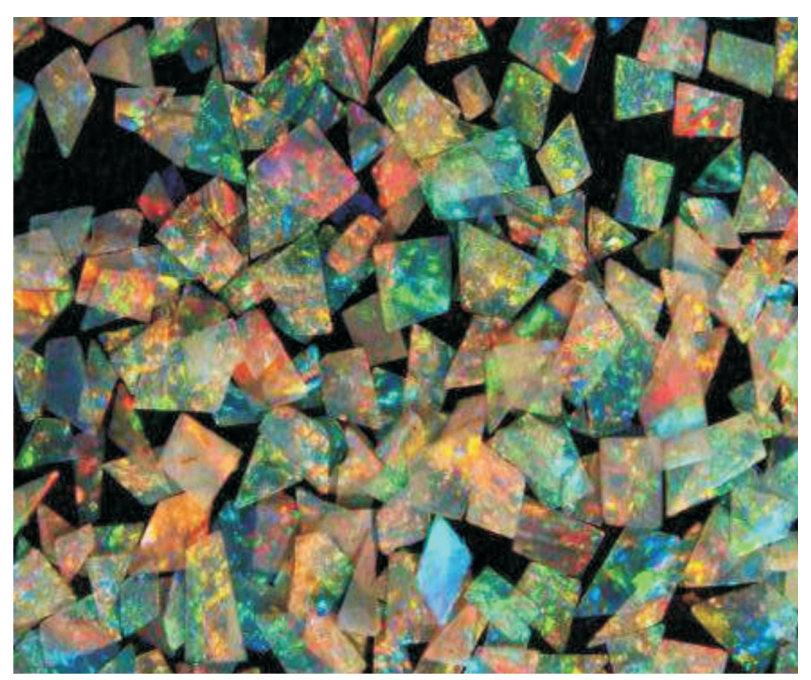

Figura 32 - Uso de minas e garimpos em roteiro de turismo mineral. Opala nobre produzida em Pedro II (PI).

\section{CONSIDERAÇÕES FINAIS}

Há poucos anos as pesquisas em geologia, que eram voltadas quase exclusivamente para a prospecção mineral, incorporaram a discussão do meio ambiente ao ensino e à pesquisa, sintonizando rapidamente com as exigências de uma conscientização mundial sobre as relações do homem com seu habitat. As inúmeras linhas de pesquisa, teses e publicações que surgiram deram novo corpo ao estudo da geologia, inclusive aprimorando e adaptando a extração mineral para minimização de impactos.

A dependência do homem com relação a extração/uso mineral evoluiu da coleta (como os recursos bióticos) até as grandes minas, que são uma forma elaborada de coleta (extração). Pode se observar desde a pré-história exemplos desta dependência em três linhas básicas que conduzem ao avanço cultural e tecnológico:

1. Os registros do homem feito em pedras e com insumos minerais, evoluindo para as tintas, o uso do grafite e o laser.

2. As habitações que inicialmente usam a própria paisagem em forma de grutas, lapas e cavernas, seguida da moldagem de barro em varas, evoluindo até o vidro e as ligas metálicas.

3. A saúde e a guerra, que se confundem e se complementam, indo do bastão as pontas de flechas e facas de pedra, da pólvora e das armas de metal e ogivas nucleares as agulhas e bisturis a laser e equipamentos de radioterapias.

Algo semelhante acontece hoje quanto à inclusão da geodiversidade na ampla compreensão ambiental. Encarar certos aspectos da geodiversidade como algo valioso - Patrimônio no seu sentido mais nobre - traz à tona uma mudança de paradigma, uma nova conscientização do profissional em geociências. Incluir o meio abiótico e fazer com que a sociedade compreenda o estreito vínculo da biodiversidade com a geodiversidade são hoje necessidades prementes. A visão segmentada do meio ambiente dos anos passados não serve mais num mundo globalizado de hoje, que acompanha os processos naturais de transformação do planeta - terremotos, tsunamis, furacões, vulcões - em tempo real.

Assim, conhecer essa parte do patrimônio natural, relacionado ao meio abiótico é de suma importância e o nordeste brasileiro tem uma diversidade geológica ímpar e que faz parte do patrimônio geológico nacional. Percebe-se, por fim, que a região nordeste do Brasil, em termos de minerais, rochas, fósseis, paisagens (relevo) e outros elementos da geodiversidade, apresenta exemplos dos mais didáticos e completos, indo desde rochas antigas do embasamento cristalino (> 3 bilhões de anos) até as coberturas de dunas ( $<5$ mil anos) e sedimentos recentes em seus leitos de rios, lagos e lagunas. Muitos desses exemplos constituem potenciais monumentos, que vêm atualmente despertando, além do interesse científico-didático, também interesses turístico, histórico e cultural. Tão importante quanto, é o potencial nordestino em termos de patrimônio mineiro. 


\section{Referencias}

ALBERTÃO G.A., MARTINS JR. P.P. 2009. Estratos calcários da Pedreira Poty (Paulista), PE: evidências de evento catastrófico no primeiro registro do limite K-T descrito na América do Sul. In: WINGE M., SCHOBBENHAUS C., SOUZA C.R.G., FERNANDES A.C.S., QUEIROZ E.T., BERBERT-BORN M., CAMPOS D.A. (Edit.) Sítios Geológicos e Paleontológicos do Brasil. Brasília: DNPM/CPRM - Comissão Brasileira de Sítios Geológicos e Paleobiológicos (SIGEP), v. 2, p. 277-290.

AULER A., ZOGBI, L. 2005. Espeleologia: noções básicas. Redespeleo Brasil, São Paulo, $104 \mathrm{p}$.

AULER A.S., SMART P.L. 2002. Toca da Boa Vista (Campo Formoso), BA: a maior caverna do hemisfério sul. In: SCHOBBENHAUS C., CAMPOS D.A., QUEIROZ E.T, WINGE, M., BERBERT-BORN, M. (Eds.). Sítios geológicos e paleontológicos do Brasil. Brasília: DNPM/CPRM - Comissão Brasileira de Sítios Geológicos e Paleobiológicos (SIGEP), v. 1, p. 443451.

BARRETO A.M.F., ASSIS H.M.B., BEZERRA F.H.R., SUGUIO K. 2010. Arrecifes, a Calçada do Mar de Recife, PE Importante registro holocênico de nível relativo do mar acima do atual. In: WINGE M., SCHOBBENHAUS C., SOUZA C.R.G., FERNANDES A.C.S., BERBERT-BORN M., SALLUN FILHO W., QUEIROZ E.T. (Edit.) Sítios Geológicos e Paleontológicos do Brasil. Publicado na Internet em 27/10/2010 no endereço http://sigep.cprm.gov.br/sitio040/sitio040.pdf

BERBERT-BORN M., KARMANN I. 2002. Lapa dos Brejões - Vereda Romão Gramacho, Chapada Diamantina, BA: gigantesca caverna e vale cárstico com rico depósito de fósseis do Quaternário. In: SCHOBBENHAUS C., CAMPOS D.A., QUEIROZ E.T., WINGE M., BERBERT-BORN M. (Edit.) Sítios Geológicos e Paleontológicos do Brasil. Brasília: DNPM/CPRM - Comissão Brasileira de Sítios Geológicos e Paleobiológicos (SIGEP), v. 1, p. 469479.

BRILHA J. 2005. Patrimônio Geológico e Geoconservação: a Conservação da Natureza na sua Vertente Geológica. Palimage Editores, 190p.

CAPUTO M.V., PONCIANO L.C.M.O. 2010. Pavimento Estriado de Calembre, Brejo do Piauí: registro de geleiras continentais há 360 milhões de anos no Nordeste do Brasil. In: WINGE M., SCHOBBENHAUS C., SOUZA C.R.G., FERNANDES A.C.S., BERBERT-BORN M., SALLUN FILHO W., QUEIROZ E.T. (Edit.) Sítios Geológicos e Paleontológicos do Brasil. Publicado na Internet em 01/07/2010 no endereço http://sigep.cprm.gov.br/sitio052/sitio052.pdf.

CARVALHO A.M., CLAUDINO-SALES V., MAIA, L.P., CASTRO J.W.A. 2009 . Eolianitos de Flecheiras/Mundaú, Costa Nordeste do Estado do Ceará, Brasil: registro ímpar de um paleo-sistema eólico costeiro.In: WINGE M., SCHOBBENHAUS C., SOUZA C.R.G., FERNANDES A.C.S., QUEIROZ E.T., BERBERT-BORN M., CAMPOS D.A. (Edit.) Sítios Geológicos e Paleontológicos do Brasil. Brasília: DNPM/CPRM - Comissão Brasileira de Sítios Geológicos e Paleobiológicos (SIGEP), v. 2, p. 121-130.

CORTÉS A.G. 1996. Inventario del Patrimonio Geológico. In MOPTMA - Min. Obr. Públ. Tranp. Med. Amb. El patrimonio geológico. Bases para su valoración, protección, conservación y utilización. Madrid.

DELLA FAVERA J.C. 2002. Parque Nacional de Sete Cidades, $\mathrm{PI}$ : magnífico monumento natural. In: SCHOBBENHAUS C., CAMPOS D.A., QUEIROZ E.T., WINGE M., BERBERT-BORN M. (Edit.) Sítios Geológicos e Paleontológicos do Brasil. Brasília: DNPM/CPRM - Comissão Brasileira de Sítios Geológicos e Paleobiológicos (SIGEP), v. 1, p. 335-342.

DOMINGUEZ J.M.L., MARTIN L., BITTENCOURT A.C.S. 2002. A Costa do Descobrimento: a geologia vista das caravelas. In: SCHOBBENHAUS C., CAMPOS D.A., QUEIROZ E.T., WINGE M., BERBERT-BORN M. (Edit.) Sítios Geológicos e Paleontológicos do Brasil. Brasília: DNPM/CPRM - Comissão Brasileira de Sítios Geológicos e Paleobiológicos (SIGEP), v. 1, p. 233-241.

GUERIN C., FAURE M., SIMÕES P.R., HUGUENEY M., MOURER-CHAUVIRE C. 2002. Toca da Janela da Barra do Antonião, São Raimundo Nonato, PI: rica fauna pleistocênica e registro da pré-história brasileira. In: SCHOBBENHAUS C., CAMPOS D.A., QUEIROZ E.T., WINGE M., BERBERT-BORN M. (Edit.) Sítios Geológicos e Paleontológicos do Brasil. Brasília: DNPM/CPRM - Comissão Brasileira de Sítios Geológicos e Paleobiológicos (SIGEP), v. 1, p. 131-137.

JULIO J., MAGINI C., MAIA L.P., CASTRO J.W.A. 2012. Ponta de Jericoacoara, CE - Belo promontório de rochas neoproterozoicas associadas a praias e dunas quaternárias com registros de variações do nível do mar. In: WINGE M., SCHOBBENHAUS C., SOUZA C.R.G., FERNANDES A.C.S., BERBERT-BORN M., SALLUN FILHO W., QUEIROZ E.T. (Edit.) Sítios Geológicos e Paleontológicos do Brasil. Publicado na Internet em 21/12/2012 no endereço http://sigep.cprm.gov.br/sitio059/sitio059.pdf

KARMANN I., PEREIRA R.G.F.A., MENDES L.F. 2002. Poço Encantado, Chapada Diamantina (Itaetê), BA: caverna com lago subterrâneo de rara beleza e importância científica. In: SCHOBBENHAUS C., CAMPOS D.A., QUEIROZ E.T., WINGE M., BERBERT-BORN M. (Edit.) Sítios Geológicos e Paleontológicos do Brasil. Brasília: DNPM/CPRM - Comissão Brasileira de Sítios Geológicos e Paleobiológicos (SIGEP), v. 1, p. 491-498.

KELLNER A.W.A. 2002. Membro Romualdo da Formação Santana, Chapada do Araripe, CE: um dos mais importantes depósitos fossilíferos do Cretáceo brasileiro. In: SCHOBBENHAUS C., CAMPOS D.A., 
QUEIROZ E.T., WINGE M., BERBERT-BORN M. (Edit.) Sítios Geológicos e Paleontológicos do Brasil. Brasília: DNPM/CPRM - Comissão Brasileira de Sítios Geológicos e Paleobiológicos (SIGEP), v. 1, p. 121129.

LAUREANO F.V., CRUZ JR. F.W. 2002. Grutas do Iraquara (Iraquara, Seabra e Palmeiras), BA: um dos principais sítios espeleológicos do Brasil. In: SCHOBBENHAUS C., CAMPOS D.A., QUEIROZ E.T., WINGE M., BERBERTBORN M. (Edit.) Sítios Geológicos e Paleontológicos do Brasil. Brasília: DNPM/CPRM - Comissão Brasileira de Sítios Geológicos e Paleobiológicos (SIGEP), v. 1, p. 461-468.

LEONARDI G., CARVALHO I.S. 2002. Icnofósseis da Bacia do Rio do Peixe, PB: o mais marcante registro de pegadas de dinossauros do Brasil. In: SCHOBBENHAUS C., CAMPOS D.A., QUEIROZ E.T., WINGE M., BERBERT-BORN M. (Edit.) Sítios Geológicos e Paleontológicos do Brasil. Brasília: DNPM/CPRM - Comissão Brasileira de Sítios Geológicos e Paleobiológicos (SIGEP), v. 1, p. 101111.

LICCARDO, A., NASCIMENTO, M.A.L. 2008. Geoturismo roteiro de turismo mineral no Nordeste. In: Cong. Bras. de Geol., 44, Curitiba, v. 1, p.394.

NASCIMENTO M.A.L., RUCHKYS Ú.A., MANTESSO NETO V. 2008. Geodiversidade, Geoconservação e Geoturismo: trinômio importante para proteção do patrimônio geológico. Sociedade Brasileira de Geologia, São Paulo, 82p.

PEDREIRA A.J., BOMFIM L.F.C. 2002. Morro do Pai Inácio, BA: marco morfológico da Chapada Diamantina. In: SCHOBBENHAUS C., CAMPOS D.A., QUEIROZ E.T., WINGE M., BERBERT-BORN M. (Edit.) Sítios Geológicos e Paleontológicos do Brasil. Brasília: DNPM/CPRM - Comissão Brasileira de Sítios Geológicos e Paleobiológicos (SIGEP), v. 1, p. 307312.

PEDREIRA A.J., ROCHA A.J.D. 2002. Serra do Tombador, Chapada Diamantina, BA: registro de um deserto proterozóico. In: SCHOBBENHAUS C., CAMPOS D.A., QUEIROZ E.T., WINGE M., BERBERT-BORN M. (Edit.) Sítios Geológicos e Paleontológicos do Brasil. Brasília: DNPM/CPRM - Comissão Brasileira de Sítios Geológicos e Paleobiológicos (SIGEP), v. 1, p. 181186.

PEDREIRA A.J. 2002. Canyon do Rio Sergi, BA: feições desérticas do Jurássico. In: SCHOBBENHAUS C., CAMPOS D.A., QUEIROZ E.T., WINGE M., BERBERTBORN M. (Edit.) Sítios Geológicos e Paleontológicos do Brasil. Brasília: DNPM/CPRM - Comissão Brasileira de Sítios Geológicos e Paleobiológicos (SIGEP), v. 1, p. 243-248.

PEDREIRA A.J. 2002. Serra do Sincorá, Chapada Diamantina, BA: beleza paisagística e paleopláceres de diamante. In: SCHOBBENHAUS C., CAMPOS D.A., QUEIROZ E.T., WINGE M., BERBERT-BORN M. (Edit.)
Sítios Geológicos e Paleontológicos do Brasil. Brasília: DNPM/CPRM - Comissão Brasileira de Sítios Geológicos e Paleobiológicos (SIGEP), v. 1, p. 187194.

PEREIRA R.G.F.A. 2010. Geoconservação e desenvolvimento sustentável na Chapada Diamantina (Bahia - Brasil). Tese de Doutorado. Escola de Ciências, Universidade de Minho, Portugal, $295 \mathrm{p}$.

PONCIANO L.C.M.O., FONSECA V.M.M., FERNANDES A.C.S., MACHADO D.M.C., SOUZA A.R. 2010. Afloramento Fossilífero de Oiti, Bacia do Parnaíba, PI: Registro de um mar devoniano no Nordeste do Brasil. In: WINGE M., SCHOBBENHAUS C., SOUZA C.R.G., FERNANDES A.C.S., BERBERT-BORN M., SALLUN FILHO W., QUEIROZ E.T. (Edit.) Sítios Geológicos e Paleontológicos do Brasil. Publicado na Internet em $18 / 01 / 2010$ no e nde reço http://sigep.cprm.gov.br/sitio051/sitio051.pdf

PORPINO K.O., SANTOS JÚNIOR V., SANTOS M.F.C.F. 2009. Lajedo de Soledade, Apodi, RN: ocorrência peculiar de megafauna fóssil quaternária no Nordeste do Brasil. In: WINGE M., SCHOBBENHAUS C., SOUZA C.R.G., FERNANDES A.C.S., QUEIROZ E.T., BERBERTBORN M., CAMPOS D.A. (Edit.) Sítios Geológicos e Paleontológicos do Brasil. Brasília: DNPM/CPRM Comissão Brasileira de Sítios Geológicos e Paleobiológicos (SIGEP), v. 2, p. 403-412.

SCHOBBENHAUS C., SILVA C.R. 2012. Geoparques do Brasil: propostas. CPRM - Serviço Geológico do Brasil, $745 p$.

SCHOBBENHAUS C., CAMPOS D.A., QUEIROZ, E.T., WINGE, M., BERBERT-BORN, M.L.C. 2002. Sítios Geológicos e Paleontológicos do Brasil. 1a Ed., Brasília. DNPM/CPRM. Comissão Brasileira de Sítios Geológicos e Paleobiológicos (SIGEP), v. 01, 554p.

SÍTIOS GEOLÓGICOS E PALEONTOLÓGICOS DO BRASIL. Propostas aprovadas de sítios e disponíveis para d e s c r i ção. D i s pon íve l e m : <http://sigep.cprm.gov.br/quadro.htm\#2>. Acesso em: 26 mar. 2013.

SOUSA D.C., JARDIM DE SÁ, E.F., VITAL, H., NASCIMENTO M.A.L. 2009. Falésias na Praia de Ponta Grossa, Icapuí, CE: importantes deformações tectônicas cenozóicas em rochas sedimentares da Formação Barreiras. In: WINGE M., SCHOBBENHAUS C., SOUZA C.R.G., FERNANDES A.C.S., QUEIROZ E.T., BERBERTBORN M., CAMPOS D.A. (Edit.) Sítios Geológicos e Paleontológicos do Brasil. Brasília: DNPM/CPRM Comissão Brasileira de Sítios Geológicos e Paleobiológicos (SIGEP), v. 2, p. 501-512.

SRIVASTAVA N.K., ROCHA A.J.D. 2002a. Fazendo Cristal, BA: estromatólitos mesoproterozóicos. In: SCHOBBENHAUS C., CAMPOS D.A., QUEIROZ E.T., WINGE M., BERBERT-BORN M. (Edit.) Sítios Geológicos e Paleontológicos do Brasil. Brasília: DNPM/CPRM - Comissão Brasileira de Sítios 
Geológicos e Paleobiológicos (SIGEP), v. 1, p. 87-93.

SRIVASTAVA N.K., ROCHA A.J.D. 2002b. Fazenda Arrecife,

BA: estromatólitos neoproterozóicos. In: SCHOBBENHAUS C., CAMPOS D.A., QUEIROZ E.T., WINGE M., BERBERT-BORN M. (Edit.) Sítios Geológicos e Paleontológicos do Brasil. Brasília: DNPM/CPRM - Comissão Brasileira de Sítios Geológicos e Paleobiológicos (SIGEP), v. 1, p. 95-100.

VIANA M.S.S., NEUMANN V.H.L. 2002. Membro Crato da Formação Santana, Chapada do Araripe, CE: riquíssimo registro da fauna e flora do Cretáceo. In: SCHOBBENHAUS C., CAMPOS D.A., QUEIROZ E.T., WINGE M., BERBERT-BORN M. (Edit.) Sítios Geológicos e Paleontológicos do Brasil. Brasília: DNPM/CPRM - Comissão Brasileira de Sítios Geológicos e Paleobiológicos (SIGEP), v. 1, p. 113120.

WINGE M., SCHOBBENHAUS C., SOUZA C.R.G., FERNANDES A.C.S., QUEIROZ E.T., BERBERT-BORN M.L.C., CAMPOS D.A. 2009. Sítios Geológicos e Paleontológicos do Brasil. 1a Ed., Brasília. CPRM. Comissão Brasileira de Sítios Geológicos e Paleobiológicos (SIGEP), v. 02, 515p.

WINGE M., SCHOBBENHAUS C., SOUZA C.R.G., FERNANDES A.C.S., QUEIROZ E.T., BERBERT-BORN M.L.C., CAMPOS D.A. (Ed.). Sítios geológicos e paleontológicos do Brasil: novas descrições publicadas na Internet. Pre print do volume 3 . Dis poníve l e m : <http://sigep.cprm.gov.br/sitios.htm\#Internet>. Acesso em: 26 mar. 2013.

XIMENES C.L. 2009. Tanques Fossilíferos de Itapipoca, CE: bebedouros e cemitérios de megafauna préhistórica. In: WINGE M., SCHOBBENHAUS C., SOUZA C.R.G., FERNANDES A.C.S., QUEIROZ E.T., BERBERTBORN M., CAMPOS D.A. (Edit.) Sítios Geológicos e Paleontológicos do Brasil. Brasília: DNPM/CPRM Comissão Brasileira de Sítios Geológicos e Paleobiológicos (SIGEP), v. 2, p. 465-478. 